\title{
Adenosine receptors as promising targets for the management of ocular diseases
}

\author{
Eleonora Spinozzi ${ }^{1}$ - Cecilia Baldassarri ${ }^{1}$ - Laura Acquaticci ${ }^{1}$ - Fabio Del Bello ${ }^{1}$ Mario Grifantini ${ }^{1}$. \\ Loredana Cappellacci ${ }^{1} \cdot$ Petrelli Riccardo $\mathbb{B}^{1}$
}

Received: 2 November 2020 / Accepted: 1 December 2020 / Published online: 25 January 2021

(C) The Author(s), under exclusive licence to Springer Science+Business Media, LLC part of Springer Nature 2021

\begin{abstract}
The ocular drug discovery arena has undergone a significant improvement in the last few years culminating in the FDA approvals of 8 new drugs. However, despite a large number of drugs, generics, and combination products available, it remains an urgent need to find breakthrough strategies and therapies for tackling ocular diseases. Targeting the adenosinergic system may represent an innovative strategy for discovering new ocular therapeutics. This review focused on the recent advance in the field and described the numerous nucleoside and non-nucleoside modulators of the four adenosine receptors (ARs) used as potential tools or clinical drug candidates.
\end{abstract}

Keywords Adenosine receptors $\left(\mathrm{A}_{1} \mathrm{AR} \cdot \mathrm{A}_{2 \mathrm{~A}} \mathrm{AR} \cdot \mathrm{A}_{2 \mathrm{~B}} \mathrm{AR} \cdot \mathrm{A}_{3} \mathrm{AR}\right) \cdot$ Ocular diseases $\cdot$ Glaucoma $\cdot$ Intraocular pressure $\cdot$ Dry eye $\cdot$ Retinal inflammation

$\begin{array}{ll}\text { Abbreviations } \\ \text { AC } & \text { adenylyl cyclase } \\ \text { AH } & \begin{array}{l}\text { aqueous humor } \\ \text { Absorption, Distribution, Metabolism, and } \\ \text { ADME }\end{array} \\ \text { Excretion } \\ \text { AMD } & \begin{array}{l}\text { age-related macular degeneration } \\ \text { adenosine receptors }\end{array} \\ \text { ARs } & \text { congestive heart failure } \\ \text { DE } & \text { dry eye } \\ \text { DR } & \text { diabetic retinopathy } \\ \text { ERK } & \text { signal-regulated kinase } \\ \text { HCC } & \text { hepatocellular carcinoma } \\ \text { INL } & \text { the inner outer layer } \\ \text { IOP } & \text { intraocular pressure } \\ \text { IP3 } & \text { inositol triphosphate }\end{array}$

This study is dedicated to Prof. Robert Vince, an exceptionally gifted scientist with a true passion for Medicinal Chemistry, on the occasion of his $80^{\text {th }}$ birthday.

Loredana Cappellacci

loredana.cappellacci@unicam.it

$\triangle$ Petrelli Riccardo

riccardo.petrelli@unicam.it

1 School of Pharmacy Medicinal Chemistry Unit, University of Camerino, Via S. Agostino 1, 62032 Camerino, Italy
MMP-2 matrix metalloproteins

NASH nonalcoholic steatohepatitis

NFL nerve fiber layer

NPE non-pigmented ciliary epithelial

NTPDase ecto-nucleoside triphosphate

diphosphohydrolase

ONH optic nerve head

ONL outer nuclear layer

PACG primary angle-closure glaucoma

PD Parkinson's disease

PLC phospholipase C

POAG primary open-angle glaucoma

RGCs retinal ganglion cells

RNFL retinal nerve fiber layer

ROCK rho kinase

RPE retinal pigment epithelium

SC scleroderma

SNMS servo-null micropipette system

TM trabecular meshwork

VEGF vascular endothelial growth factor.

\section{Introduction}

The eye is a unique and complex organ considered the "window to the brain" and the disruption of any of its tissues can end up in ocular discomfort, visual impairment, or loss of vision. Its anatomical complexity makes extremely 
difficult the understanding of disease pathogenesis and ophthalmic drug discovery challenging. With respect to other tissues of the human body, the eye owns several unique features. It is an immune-privileged site that actively restrains some immune and inflammatory responses due to the presence of the blood-retinal barrier (BRB). BRB is a physical barrier that allows solutes' movements across the vascular bed and affords a primordial defense from invaders. Moreover, some of his tissues are transparent and avascular, making the eye easy to reach clinically.

Recent data released by WHO reported that about 1 billion people suffer from vision impairment, and most of them are over 50 years [1]. It seems evident that the leading causes of visual impairment are age-related and include the following ocular diseases: glaucoma, dry eye (DE), retinal inflammation, age-related macular degeneration (AMD), and diabetic retinopathy (DR).

Glaucoma is an aetiologically complex optic neuropathy distinguished by the accelerated death of axons and retinal ganglion cells (RGCs). Regretfully, it is considered the second most frequent cause of irreversible blindness worldwide [2-4]. In 2014, Tham et al. have performed a systematic population-based meta-analysis study anticipating that the global glaucoma burden will grow from 76 million in 2020 to 112 million in 2040, mainly affecting people living in low-income countries such as Africa and Asia [5]. The disease covers a broad and complex group of optic neuropathies defined by a progressive loss of RGCs and associated alterations in the optic nerve head (ONH) and the retinal nerve fiber layer (RNFL), with resultant vision loss [6]. Even though the exact explanation of the etiopathogenesis is yet unclear, the elevation of intraocular pressure (IOP) represents the only known treatable risk factor [7]. Hence, IOP might be considered the pillar target in contemporary glaucoma management [8], and its reduction is deemed as the primary efficacy endpoint in almost all ongoing glaucoma clinical trials.

Primary angle-closure glaucoma (PACG) and primary open-angle glaucoma (POAG) are the two most common primary glaucoma types. Although they have some common characteristics, they have completely different etiopathogenesis, leading up to different pharmacological approaches. POAG is the most prevalent type of glaucoma in western Europe and the United States. On the contrary, PACG is highly frequent in China and other Asian countries.

A broad range of pharmacological and surgical options are available for glaucoma treatment, including eye drops and laser procedures. All are meant to protect the optic nerve by decreasing eye pressure. In spite of the full availability of different options, eye drops often represent the first choice for treating patients. Eye pressure can be safely controlled for many years using a combination of drugs and laser treatments. The mechanism of action by which the eye drops operate through is by helping the eye's fluid to drain off or by cutting down the fluid load produced by the eye. Drug treatments used for glaucoma management are ranked based on their active components, including carbonic anhydrase inhibitors, alpha agonists, beta-blockers, and prostaglandin analogs. Patients who demand more than one type of medication are often treated with a combination of different drugs. The older class of cholinergic agonists (such as carbachol and pilocarpine) represents the first class of drugs used to manage glaucoma and operates by lowering IOP through increasing aqueous humor (AH) outflow. However, due to their severe systemic side effects, they have now fallen into disuse. The brand-new FDA-approved rho kinase (ROCK) inhibitor, Rhopressa (Netarsudil ophthalmic solution, Aerie Pharmaceuticals), reduces IOP by lowering the elevated pressure in patients with POAG or ocular hypertension. The drug exerts its pharmacological effect by increasing the outflow of $\mathrm{AH}$ or by the inhibition of norepinephrine transport along with reducing the episcleral venous pressure [9]. Just recently, the US FDA approved Roclatan (a combination of latanoprost and netarsudil) to manage POAG [10]. The combination relies on the ability of netarsudil to loweringIOP complemented by the latanoprost-mediated increase of outflow. Vyzulta (latanoprostene ophthalmic solution, LBN), licensed by Bausch \& Lomb and FDA approved in 2017, is nitric oxide (NO)-donating PGF2 $\alpha$ analog that demonstrated a high potential for lowering IOP [10].

The DE syndrome is often known by a variety of terms ranging from keratitis sicca, keratoconjunctivitis sicca (KCS), to dysfunctional tear syndrome. In DE the eye turns into dry either because there are not enough tears being produced or because there is an abnormal evaporation of tears. In an eye suffering from DE, the tears' content seems to be impaired with a lesser concentration of proteins, and one of the characteristic features of DE is ocular surface inflammation. Tear supplements represent the first-line treatments for mild dry eye disease (DED), whereas cyclosporine and Lifitegrast ${ }^{\oplus}$ result to be appropriate choices in patients with more severe symptoms [11].

Neuroinflammation, a feature of chronic neurodegenerative diseases, plays an essential role in several retinal degenerative diseases' pathophysiology [12]. The retina is a complex and highly organized tissue made of neuronal and non-neuronal cells. Neurons aside, the retina also contains endothelial cells, pericytes, and glial cells named astrocytes, microglia, and Müller cells. An intact BRB is essential in protecting neural tissues from harmful materials and maintaining the retina's neural functions. It is well documented that an inflammatory insult impacts negatively on the BRB's integrity. The immune cells respond to an insult by secretion of pro-inflammatory cytokines that contribute to 
endothelial cell dysfunction, inducing retinal cell death, and BRB breakdown. It has been reported that a proinflammatory environment is a breeding ground for the onset of glaucoma and DR. Based on these findings, fighting the actions of pro-inflammatory cytokines has been proposed as an innovative therapeutic strategy for managing retinal inflammation [13].

AMD is the leading cause of severe and irreversible loss of vision in patients aged 60 or over [14]. This disease causes damage to the macula, the central part of the retina responsible for high-resolution vision, and is due to an anomaly (e.g., structural changes and a general decline of essential functions) of retinal pigment epithelium (RPE) [15]. Current known risk factors include age, people with a family history of AMD, smokers, ethnicity (high incidence in Caucasians), gender (high incidence in women), and race. Anti-vascular endothelial growth factor (VEGF) therapy is regarded as the first-line treatment for AMD and aims to reduce edema and neovascularization (new blood vessel growth). Anti-VEGF therapy has tremendously decreased the prevalence of AMD globally [16].

DR is a complication of diabetes mellitus that leads to vision loss through progressive damage in retinal blood vessels [17]. People of all ages who have had diabetes for more than 20 years have the maximum probability of developing DR. The recent therapeutic trend for managing DR foresees the intravitreal administration of anti-VEGF with the goal of improving vision with fewer side effects. On the other side, the laser therapy facilitates to stabilize the vision.

The ocular therapeutic field has achieved significant improvements in the last decade, as evidenced by the FDA approval of Lifitegrast (an integrin antagonist) for DE,

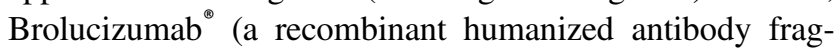
ment) for wet AMD, Roclatan (a combination product),

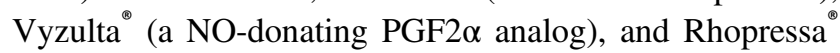
(ROCK inhibitor) for glaucoma, Luxturna (gene therapy) for retinitis pigmentosa and Dextenza (a corticosteroid) for ocular inflammation. However, despite all the efforts to develop new drugs, generics, and innovative therapies, the successful management of ocular diseases still lingers as an unmet medical need.

Among the multitude of transmitters/modulators present in the eye, nucleosides and nucleotides emerge as peculiar molecules able to regulate many physiopathological and biochemical processes.

For this reason, the purinergic signaling pathways are increasingly becoming recognized in ophthalmology as a potential target for pharmaceuticals. In particular, the adenosine signaling pathway, including its sub-receptor biology, is increasingly being investigated to develop new ophthalmic drugs. Different categories of agonists and antagonists of various subtypes of $G$ protein-coupled receptors such as adenosine receptors (ARs) and $\mathrm{P} 2 \mathrm{Y}$ receptors (P2YRs), and ATP-gated $\mathrm{P} 2 \mathrm{X}$ receptor ion channels (P2XRs) are currently under investigation as potential agents for the treatment of DE, ocular inflammation, and glaucoma [18-20]. Three out of four subtypes of ARs $\left(A_{1}, A_{2 A}\right.$, and $A_{3}$, respectively) have extensively been exploited to treat eye disorders, yielding some clinical candidates [21-23].

It is also worth mentioning that extracellular concentrations of dinucleoside polyphosphates are significantly increased in pathological states, activating P2YRs and P2XRs throughout the eye. P2YRs and P2XRs have multiple functions in the eye, and their modulation has been explored for ophthalmic drug discovery purposes. P2Y2R and P2Y6R agonists lower IOP, whereas the P2X7R antagonists thwart the ATP-induced neuronal apoptosis in the retina. For the above reasons, the modulators of the "purinome" present in the eye might represent a valuable source of new therapeutic options for ocular diseases. In this context, this review provides an overview of recent ocular drug discovery literature covering this emerging and dynamic field.

\section{Rationale for treating ocular diseases via adenosine receptor agonists and antagonists}

The endogenous nucleoside modulator adenosine is continuously produced both at the intracellular and extracellular levels. It has a very short half-life $(\sim 1.5 \mathrm{~s})$, and it is quickly metabolized to inosine and hypoxanthine. In the CNS, adenosine controls synaptic activity, neurotransmitter release, and neuronal excitability, acting as a neuromodulator. It may also act as an intracellular messenger embroiled in pathological and physiological processes (e.g., inflammation). Low extracellular levels of adenosine (in the nanomolar level) are deemed as positive signs of cellular homeostasis, as usually occurs during physiological conditions. In response to cellular stress or pathological conditions (e.g., ischemia or tissue hypoxia), the adenosine levels considerably increase, reaching the micromolar range [24]. If we compared the normotensive individuals with ocular hypertensive patients, it could easily be observed that the adenosine levels in $\mathrm{AH}$ are significantly boosted [25, 26].

The biological functions of adenosine are mediated by activation of four different G-coupled ARs: $A_{1} A R, A_{2 A} A R$, $\mathrm{A}_{2 \mathrm{~B}} \mathrm{AR}$, and $\mathrm{A}_{3} \mathrm{AR}$, respectively. All of them are implicated in inhibiting and stimulating cyclic AMP (cAMP) production in several manners. By giving details, $\mathrm{A}_{1} \mathrm{AR}$ and $\mathrm{A}_{3} \mathrm{AR}$ down-regulate cAMP levels inhibiting adenylyl cyclase (AC), whereas $\mathrm{A}_{2 \mathrm{~A}} \mathrm{AR}$ and $\mathrm{A}_{2 \mathrm{~B}} \mathrm{AR}$ activate $\mathrm{AC}$, boosting cAMP production. 
Fig. 1 Chemical structures of compounds 1-6
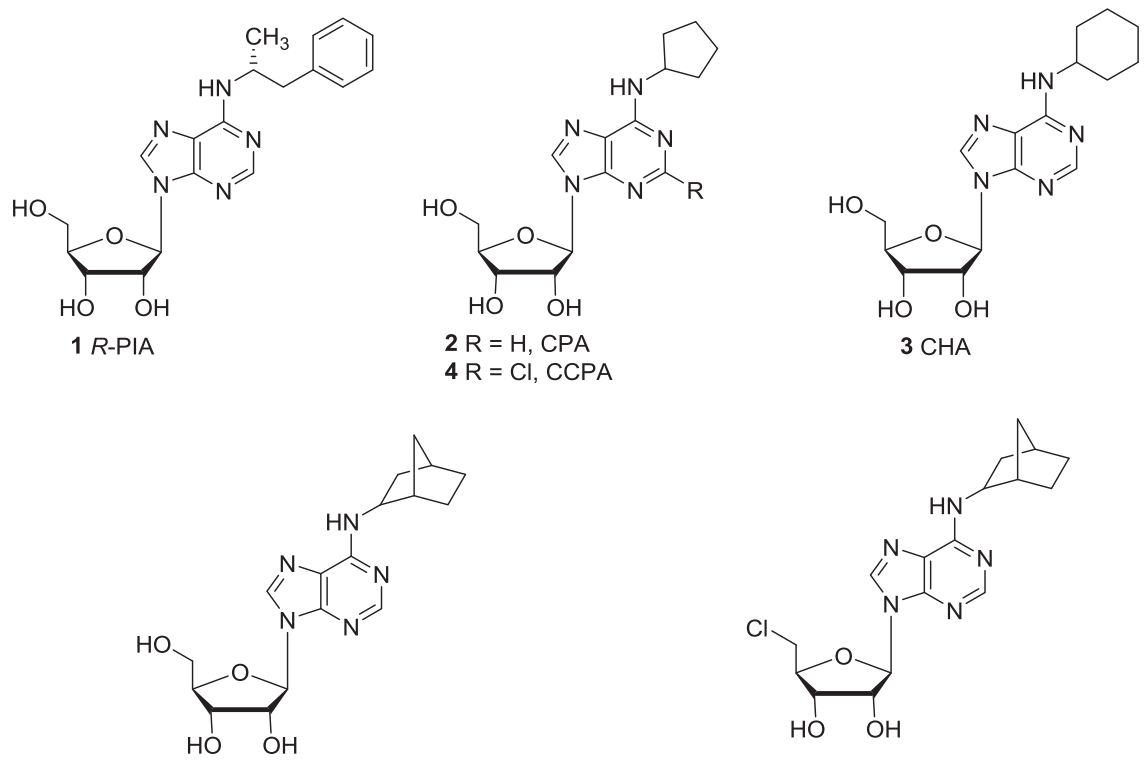

5 (S)-ENBA

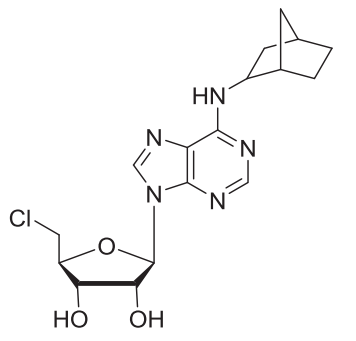

$65^{\prime}-\mathrm{Cl}-\mathrm{ENBA}\left(5^{\prime} \mathrm{Cl} 5^{\prime} \mathrm{d}-( \pm)-\mathrm{ENBA}\right)$
Besides being widely distributed in the whole body, ARs are worthy of special mention in numerous ocular tissues such as the ciliary body, trabecular meshwork (TM), scleroderma (SC), and retina [27]. Activation or inactivation of ARs crashes onto AH formation, outflow, and as a consequence on IOP homeostasis. Furthermore, ARs are implicated in retinal function neuronal, deeply affecting neuronal survival and blood flow [25]. For the above reasons, the modulation of ARs has been explored for several decades as an insightful strategy for treating ocular diseases. Nowadays, there is a readily-available arsenal of potent agonists and antagonists associated with each of the four AR subtypes. However, cautiousness shall be used when they are applied to pharmacological experiments due to the selectivities that are not completely unequivocal for each AR subtype $[19,20]$. For example, the $\mathrm{A}_{1} \mathrm{AR}$ agonist $R$ phenyl isopropyl adenosine (R-PIA, 1, Fig. 1) causes reductions in body temperature and heart rate in mice which are dependent on the presence of the $\mathrm{A}_{3}$ subtype. Indeed, genetic knockout of the $\mathrm{A}_{3} \mathrm{AR}$ corroborates this hypothesis and prevents some of these effects [19,26].

\section{$A_{1} A R$ agonists}

The $\mathrm{A}_{1} \mathrm{AR}$ was the first $\mathrm{AR}$ to be cloned and is widely expressed in the brain and peripheral tissues (e.g., kidney, liver, heart, smooth muscle, fat cells, and eye) [28]. Just recently $A_{1} A R$ has been well characterized in the retina of Rhesus monkey and has been localized on the outer plexiform layer (OPL), in the RPE, in the ganglion cell layer (GCL), and on photoreceptors [29]. $A_{1}$ AR plays an essential role in inflammation, and in the brain the activation of $A_{1} A R$ weakens the ischemic neuronal impairment [30]. Retinal ischemia phenomenon is attributable to glaucoma, diabetes, central artery occlusion, and retinopathy and always ends up with vision loss. The activation of $A_{1} A R$ by selective agonists protects against ischemic impairment, probably through a mechanism that involves Müller cells. Unfortunately, this protection depends on ischemia duration and is not effective in prolonged ischemia. Another effect of $\mathrm{A}_{1} \mathrm{AR}$ activation is the attenuation of the damage caused by N-methyl-Daspartate (NMDA). Adenosine acts as a neuromodulator of RGCs by inhibiting the glutamate-induced calcium influx through the $\mathrm{A}_{1} \mathrm{AR}$ activation. In addition, adenosine binds to $A_{1} A R$ present on the $T M$, increasing the $A H$ outflow through secretion of matrix metalloproteins (MMP-2) [31]. This process has the effect of lowering IOP [32].

Adenosine is the primary endogenous agonist of the $\mathrm{A}_{1} \mathrm{AR}$, whereas countless $\mathrm{A}_{1} \mathrm{AR}$ agonists with every disparate modification at ribose moiety and the adenine $N^{6}$ and $\mathrm{C} 2$ positions have been disclosed in the last two decades [33-40]. Before the discovery of the $A_{3}$ subtype, several agonists have been identified as selective for $\mathrm{A}_{1} \mathrm{AR}$ (Fig. 1) since it has been defined their $\mathrm{A}_{1} \mathrm{AR}$ selectivity based on their affinity at the rat $\mathrm{A}_{1} \mathrm{AR}$ vs. $\mathrm{A}_{2 \mathrm{~A}} \mathrm{AR}$ [41]. However, a comparison of $N^{6}$-cyclopentyladenosine $(\mathrm{CPA}, 2)$ and $N^{6}$ cyclohexyladenosine (CHA, 3 ) binding affinities at the four human ARs showed only a limited $\mathrm{A}_{1} \mathrm{AR}$ selectivity compared to the $\mathrm{A}_{3} \mathrm{AR}$ [20]. Later on, the $\mathrm{A}_{1} \mathrm{AR}$ full agonist 2chloro- $N^{6}$-cyclopentyladenosine (CCPA, 4, Fig. 1) showed lower than full efficacy at the $\mathrm{A}_{3} \mathrm{AR}$, acting as a partial agonist or an antagonist [42] and (S)-ENBA (5, Fig. 1) emerged as an extremely selective $\mathrm{A}_{1} \mathrm{AR}$ agonist ( $>1000$ fold) respect to rat and human $\mathrm{A}_{3} \mathrm{AR}$ [43]. 


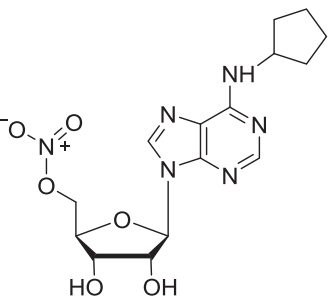

7 Trabodenoson (INO-8875, PJ-875)

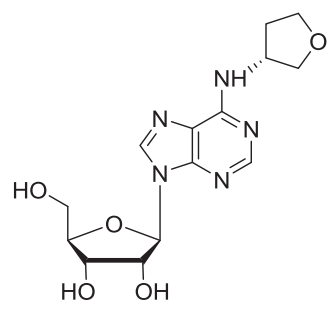

8 Tecadenoson (CVT-510)

Fig. 2 Chemical structures of trabodenoson (7) and tecadenoson (8)

However, among the most selective $\mathrm{A}_{1} \mathrm{AR}$ agonists deserve particular mention $5^{\prime}$-chloro-5'-deoxy- $N^{6}$ $( \pm)$-endo-norborn-2-yl-adenosine $\quad\left(5^{\prime} \mathrm{Cl} 5^{\prime} \mathrm{d}-( \pm)\right.$-ENBA or 5'-Cl-ENBA, 6), developed in our laboratory, which had exceptionally high $\mathrm{A}_{1} \mathrm{AR}$ affinity and selectivity versus the other AR subtypes $[44,45]$.

Trabodenoson (INO-8875, PJ-875, 7, Fig. 2), the 5'nitrate ester derived from CPA, was developed using a 3D structure and rational drug design techniques to create adenosine mimetic with a high affinity and selectivity for the $\mathrm{A}_{1} \mathrm{AR}\left(K_{\mathrm{i}}=0.97 \mathrm{nM}\right.$, partial agonist). Based on trabodenoson's high selectivity, a consistent reduction in IOP has been observed without the transient IOP increase associated with other less specific compounds that interact with other AR subtypes [21, 46]. Based on this finding, it reached the clinical trials in 2015 as an ophthalmic formulation for ocular hypertension (OHT) and POAG [47] and advanced in the phase 3 trial (ClinicalTrials.gov Identifier: NCT02565173). Unfortunately, the development was discontinued in 2017 due to failure to achieve its primary endpoint to better reduce IOP compared to placebo [23]. Despite not yet published, an important study of phase 2 (NCT02829996) reported the combination of trabodenoson (two different doses $3.0 \%$ and $6.0 \%$ ) and latanoprost $(0.005 \%$ or $0.0025 \%)$ in patients affected by OHT or POAG. Unfortunately, no significant clinical outcomes have been observed with the combination, and in 2018, Inotek, after merging with Rocket Pharma, decided to stop all the development activities.

The potent and selective $\mathrm{A}_{1} \mathrm{AR}$ full agonist Tecadenoson (CVT-510, 8, Fig. 2) has been evaluated in a phase 3 trial to terminate induced paroxysmal supraventricular tachycardia (PSVT) without showing the typical side effects caused by stimulation of other AR subtypes. Nevertheless, as other adenosine $\mathrm{A}_{1} \mathrm{AR}$ agonists (capadenoson and selodenoson), has not fared well in cardiovascular disease, and it was discontinued in 2009.

5'-Cl-ENBA (6, Fig. 1) is a potent and selective $A_{1} A R$ full agonist. It binds to the human $\mathrm{A}_{1} \mathrm{AR}\left(h \mathrm{~A}_{1} \mathrm{AR}\right)$ with an affinity at the subnanomolar level $\left(K_{\mathrm{i}}=0.5 \mathrm{nM}\right)$, showing a relevant selectivity versus the $h \mathrm{~A}_{3} \mathrm{AR}$ (2530-fold) [45]. It is also able to penetrate the blood-brain barrier efficiently [48].
As recently reported by us, 5'-Cl-ENBA can reduce pain in the formalin test or prevent mechanical allodynia and thermal hyperalgesia in the spared nerve injury (SNI) model of neuropathic pain in mice, without exerting any drawbacks on motor coordination and blood pressure $[49,50]$. It has also been reported that it can decrease 1-DOPA-induced dyskinesia and locomotor activity in a mice model of Parkinson's disease (PD) [51], as well as the harmalineinduced tremor in rats [48].

The advantage of 5'-Cl-ENBA over the other $\mathrm{A}_{1} \mathrm{AR}$ agonists lies in the fact that at effective doses, it does not affect either motor coordination, blood pressure, or heart rate, corroborating the hypothesis that it is scarcely active on the peripheral $\mathrm{A}_{1} \mathrm{AR}$. Ossowska et al. has recently investigated $5^{\prime}$-Cl-ENBA as a potential antipsychotic agent [52]. The authors reported that the hyperlocomotion induced by either amphetamine $(1 \mathrm{mg} / \mathrm{kg} \mathrm{sc})$ or MK-801 (dizocilpine) $\left(0.3 \mathrm{mg} / \mathrm{kg}\right.$ ip) was inhibited by $5^{\prime}$-Cl-ENBA $\left(0.1 \mathrm{mg} / \mathrm{kg}\right.$ ip). A selective $\mathrm{A}_{1} \mathrm{AR}$ antagonist entirely reverted the effect.

5'-Cl-ENBA has never been studied in experimental models of glaucoma and ocular hypertension. However, given its high selectivity at $\mathrm{A}_{1} \mathrm{AR}$ and the distinctive feature to not generate cardiovascular drawbacks, it should be taken into consideration for further studies.

\section{Non-nucleoside $A_{1} A R$ partial agonists}

As a consequence of the crucial involvement of $A_{1}$ agonists in heart rate and blood pressure regulation, the therapy for glaucoma or ocular hypertension built on $\mathrm{A}_{1} \mathrm{AR}$ agonists suffers from significant limitations [53]. For this reason, several non-nucleoside $\mathrm{A}_{1} \mathrm{AR}$ partial agonists have been developed [54]. The rationale for using $A_{1} A R$ partial agonists is based on avoiding receptor desensitization and on achieving a specific tissue selectivity of the effects without generating drawbacks $[55,56]$.

In 2012 Bayer HealthCare Pharmaceuticals patented a series of dicyanopyridine derivatives as potential therapeutic agents for the treatment and/or prophylaxis of glaucoma and ocular hypertension. As the outcome, the authors found out that some dicyanopyridine derivatives, and specifically capadenoson (BAY68-4986, 9, Fig. 3), lower IOP after topical eye application without affecting hemodynamics and the cardiovascular system [57]. Capadenoson (9) has been in the clinical evaluation (phase 2) in patients with persistent or permanent atrial fibrillation (AF) and angina pectoris (NCT00568945 and NCT00518921). However, 9 was withdrawn when it failed to show heart rate reduction for patients with atrial fibrillation. Just recently, it has been reported that 9 also activated human $\mathrm{A}_{2 \mathrm{~A}} \mathrm{AR}$, even though the affinities at $\mathrm{A}_{1} \mathrm{AR}$ and $\mathrm{A}_{2 \mathrm{~A}} \mathrm{AR}$ were not entirely comparable [58]. 
Fig. 3 Chemical structures of capadenoson $(\mathbf{9})$ and neladenoson bialanate (10)

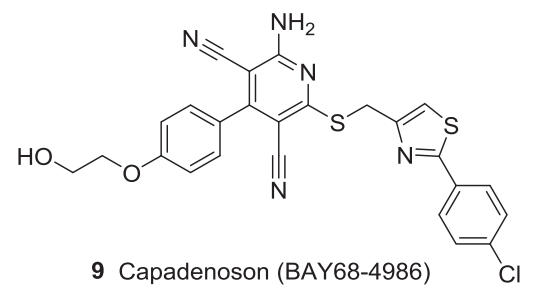

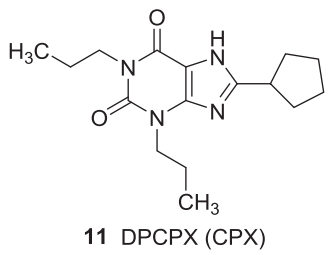
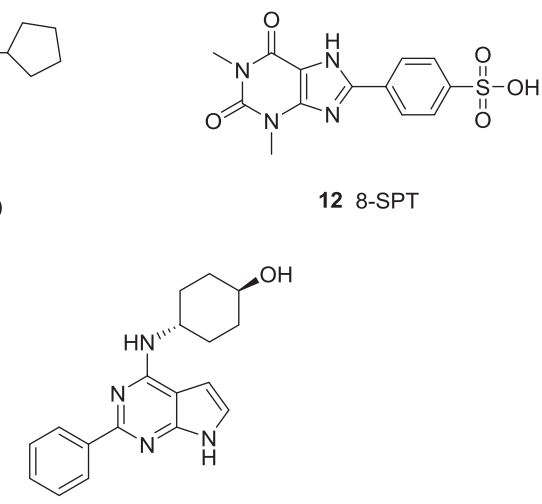

13 Derenofylline (SLV320)

Fig. 4 Chemical structures of DPCPX (11), 8-SPT (12), and derenofylline (13)

Neladenoson bialanate (BAY1067197, 10, Fig. 3), a dipeptide ester prodrug of neladenoson, has been clinically evaluated by Bayer HealthCare Pharmaceuticals in patients with chronic heart failure (NCT03098979). Unfortunately, the expected beneficial cardiac effects have not been proven while it has been observed a consistent impairment in renal function [59]. For these reasons, in 2020, Bayer decided to do not further support the development of 10, and the drug has been discontinued (NCT04320771).

\section{$A_{1} A R$ antagonists}

While the activation of $\mathrm{A}_{1} \mathrm{AR}$ lowers $\mathrm{IOP}$ in rabbits and monkeys ([60]; Tian et al., 1997), the selective action of $\mathrm{A}_{1} \mathrm{AR}$ antagonists such as DPCPX (11), 8-(p-sulfophenyl) theophylline (8-SPT, 12), and derenofylline (SLV320, 13, Fig. 4) raises IOP instead [61]. In a pioneering work aimed to evaluate the role of AR activation in epinephrine-induced changes in ocular function, Crosson et al. reported that 8SPT (12) enhanced initial hypertension by inhibiting the epinephrine-induced reduction in IOP [62]. On the other hand, the $A_{1} A R$ antagonists DPCPX diminished recovery after retinal ischemia in rats, while an $\mathrm{A}_{2 \mathrm{~A}} \mathrm{AR}$ antagonist considerably protected the retinal function and structure even with long-lasting ischemia [63].

The pyrrolo-pyrimidine derivative $\mathbf{1 3}$ has never been studied as potential drug candidate for ocular diseases.
However, it is in phase 2 clinical trials by Abbvie (previously Solvay Pharmaceuticals and Abbott) for the treatment of congestive heart failure $(\mathrm{CHF})$ and renal failure (NCT00568009). Although it has completed a phase 2 trial, no recent developments have been reported.

Taken together, those data support the idea that $A_{1} A R$ antagonists hold few promises as ocular drug candidates, given the fact they increase IOP in mice and rabbits [25].

\section{$A_{2 A} A R$ agonists}

The human $\mathrm{A}_{2 \mathrm{~A}} \mathrm{AR}$ was identified in 1992 and has been localized in the retina in several places, including GCL, outer nuclear layer (ONL), and the inner outer layer (INL) [64]. $A_{2 A} A R$ has also been detected in microglia and Müller cells [65]. In the last decade, $\mathrm{A}_{2 \mathrm{~A}} \mathrm{AR}$ has been extensively explored as a potential therapeutic target for lowering IOP or treating retinal disorders. Recently, it has been emphasized that its role played in neuroinflammation, and the modulation of its activity can shield the retinal cells from an inflammatory insult [13, 66].

$\mathrm{A}_{2 \mathrm{~A}} \mathrm{AR}$ agonists and antagonists have also been widely investigated as ocular disease therapeutics, with particular reference to glaucoma [67]. Selective $\mathrm{A}_{2 \mathrm{~A}} \mathrm{AR}$ agonists are typically amended at the $\mathrm{C} 2$ position and modified at the $\mathrm{C}^{\prime}$ of the ribose ring.

A shortlist of $\mathrm{A}_{2 \mathrm{~A}} \mathrm{AR}$ agonists that have demonstrated to lower IOP and to be useful for the treatment of glaucoma included: OPA-6566 (structure not disclosed), CGS-21680 (14), 2-O-Ado (15), 2-CN-Ado (16), and ATL-313 (17) (Fig. 5).

Otsuka Pharmaceutical Co., Ltd. (Otsuka) and Acucela, Inc. in September 2010 signed a co-development and cocommercialization agreement for the development of OPA6566 for the management of POAG or ocular hypertension. OPA-6566 went through phase 1 and 2 clinical trials (NCT01410188) due to its ability to lowering IOP by enhancing $\mathrm{AH}$ outflow via the TM. The trial has been recently completed, but no results have yet been released. Although this Otsuka Pharmaceutical decided to end up its participation in further development activities (e.g., glaucoma) for OPA-6566, exercising its contractual right to terminate the agreement with Acucela. Acucela is now called Kubota Vision and in 2019, announced to have 
Fig. 5 Chemical structures of CGS21680 (14), 2-O-Ado (15), 2-CN-Ado (16), ATL-313 (17) and apadenoson (18)

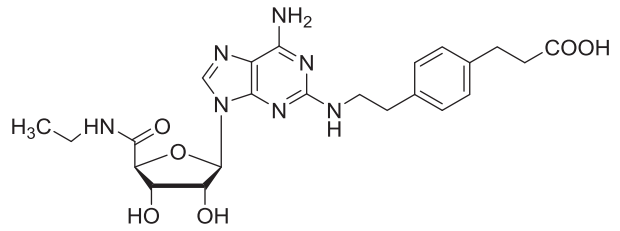

14 CGS-21680

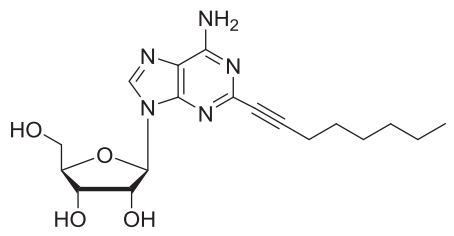

15 2-O-Ado

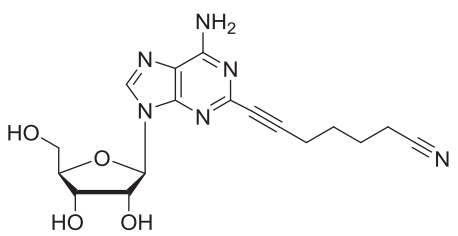

16 2-CN-Ado

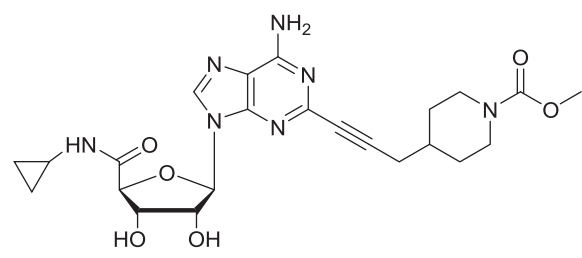

17 ATL-313 (Evodenoson)

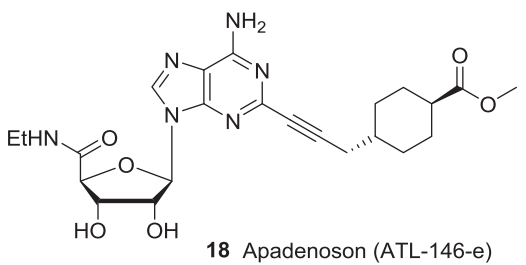

discontinued the phase 1 and 2 for managing glaucoma and ocular hypertension in the US.

In 2005 Konno et al. conducted a study with CGS21680 (14) and the 2-alkynyladenosine derivatives 2-O-Ado (15), and 2-CN-Ado (16) in order to clarify the mechanism underlying the changing of IOP observed in rabbits [67]. The results showed that $\mathbf{1 5}$ and $\mathbf{1 6}$ decreased the IOP significantly in a concentration-dependent manner, whereas the relatively selective $A_{2 A} A R$ agonist $\mathbf{1 4}$ slightly decreased IOP. Also, $\mathbf{1 5}$ and $\mathbf{1 6}$ remarkably increased cAMP levels in the $\mathrm{AH}$ after $60 \mathrm{~min}$ of their administration. The authors stated that the observed IOP decreasing could be linked to increasing of cAMP levels induced by $\mathbf{1 5}$ and 16, mediated by a rise in outflow facility.

Evodenoson (ATL-313, DE-112, 17, Fig. 5), a more stable urethane-containing analog of apadenoson (18, Fig. 5), has been developed by Santen Pharmaceutical, capitalizing on its property of lowering IOP [23]. In 2012 Santen completed a phase $1 / 2$ clinical trial investigating the safety and efficacy of ATL-313 in lowering IOP in patients with POAG or ocular hypertension (NCT01279083). The study results have been submitted to ClinicalTrials.gov but are not yet publicly available.

Over the past two decades, Pfizer developed an extensive series of $N^{6}$-(2,2-diphenylethyl)-adenosine analogs acting as potent and selective $\mathrm{A}_{2 \mathrm{~A}} \mathrm{AR}$ agonists, and UK-432097 (19, Fig. 6) has emerged as the best-in-class [68]. It has been clinically developed in phase 1 for asthma and phase 2 for chronic obstructive pulmonary disease (COPD,

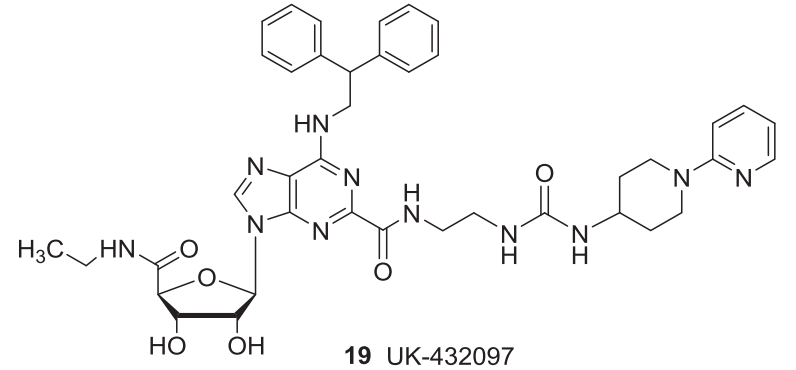

Fig. 6 Chemical structure of UK-432097 (19)

NCT00430300), failing on both. It was discontinued in 2008 for lacking efficacy [69].

Despite all efforts, the potentiality of $\mathrm{A}_{2 \mathrm{~A}} \mathrm{AR}$ agonists for the treatment of ocular diseases is uncertain since they have revealed both unfavorable and favorable effects in preclinical and clinical studies [19, 20].

It is worth mentioning that $\mathrm{A}_{2 \mathrm{~A}} \mathrm{AR}$ agonists had an antiinflammatory role in RGCs subjected to elevated pressure [70]. As reported by Ahmad et al., the administration of CGS-21680 (14) significantly attenuated the expression of inflammatory mediators (e.g., ICAM-1, IL-6, and TNF $\alpha$ ) and cell death markers in a mouse model of traumatic optic neuropathy (TON) [66]. TON is one of the significant visual repercussions of severe head trauma. The anti-inflammatory effect of $\mathbf{1 4}$ is mediated by blocking extracellular signalregulated kinase (ERK) activation and further cytokine release in TON. The role played by $\mathrm{A}_{2 \mathrm{~A}} \mathrm{AR}$ in TON has also 


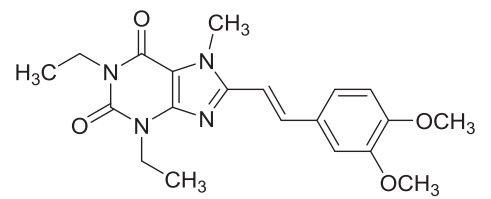

20 Istradefylline (KW-6002)

Fig. 7 Chemical structure of istradefylline (KW-6002) (20)

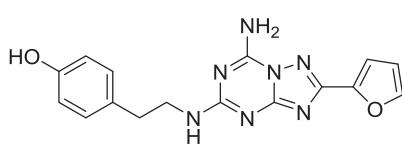

$21 \mathrm{ZM}-241385$

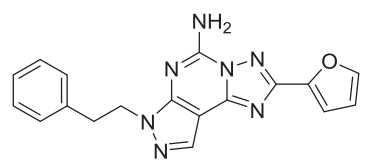

$23 \mathrm{SCH}-412348(\mathrm{SCH}-58261)$

Fig. 8 Chemical structures of ZM-241385 (21), vipadenant (BII014, V2006, 22), and SCH-412348 (SCH-58261, 23)

been evaluated in $\mathrm{A}_{2 \mathrm{~A}} \mathrm{AR}$ knockout mice, uncovering its potential as a therapeutic target in TON. Given that inflammation is a key player in the pathogenesis of glaucoma [71-73], $\mathrm{A}_{2 \mathrm{~A}} \mathrm{AR}$ agonists might be helpful. Another crucial function that they have shown, together with $A_{1} A R$ agonists, is to reduce vascular resistance and increase blood flow to the retina and $\mathrm{ONH}[25]$.

\section{$A_{2 A} A R$ antagonists}

Over the years, several $\mathrm{A}_{2 \mathrm{~A}} \mathrm{AR}$ antagonists have been synthesized, and if we would divide them by relying on their chemical structure, they can be split into xanthine and nonxanthine derivatives [74]. The xanthine derivative istradefylline (KW6002, 20, Fig. 7), developed by investigators at Kyowa Hakko Kirin, has been one of the first potent $\mathrm{A}_{2 \mathrm{~A}} \mathrm{AR}$ antagonists reported. Recently Boia et al. Boia et al. [75], reported that the blockade of $A_{2 A} A R$ might represent a therapeutic option for the treatment of retinal ischemic diseases (e.g., transient retinal ischemia). For this reason, they evaluated KW6002 against the damage induced by ischemia-reperfusion (I-R). Its oral administration after inducing ischemia reduces microglia reactivity and inflammatory response considerably, affording retina protection. This seminal work has laid the basis for further studies on.

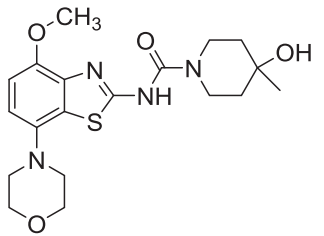

24 Tozadenant (SYN-115)

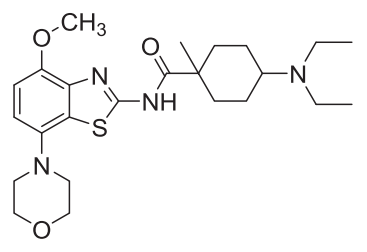

25
Fig. 9 Chemical structures of tozadenant (SYN-115, 24), and 25

$\mathrm{A}_{2 \mathrm{~A}} \mathrm{AR}$ antagonists as potential tools for managing retinal ischemic or neurodegenerative diseases. After being approved in Japan in 2013 to treat PD, istradefylline was launched in 2019 in the US (product name: NOURIANZ ${ }^{\mathrm{TM}}$ ) as an add-on therapy to levodopa/carbidopa in adults who are experiencing off episodes. The approval was based on its success in 4 clinical studies that included around 1200 participants. In January 2020, Kyowa Kirin Co., Ltd. announced that its marketing authorization application (MAA), as an adjunctive treatment for PD, had been validated by the European Medicines Agency (EMA).

Highly potent $\mathrm{A}_{2 \mathrm{~A}} \mathrm{AR}$ antagonists of the new generation are represented by triazolotriazine ZM-241385 (21, Fig. 8 ), the triazolopyrimidine vipadenant (BII014, V2006, 22), and the pyrazolotriazolopyrimidine SCH-412348 (SCH-58261, 23). The highly potent and selective $A_{2 A} A R$ antagonist, ZM-241385 (21), also binds to the human $A_{2 B} A R$ with moderate affinity, and its structure in complex with thermostabilised $\mathrm{A}_{2 \mathrm{~A}} \mathrm{AR}$ adenosine has been reported [76]. 21 also behaves as an inverse agonist [77]. Recently Liu et al. reported the effect of ZM-241385 on microglial activation in experimental glaucoma [78]. The authors showed that ZM-241385 might downregulate the activation of proinflammatory cytokines and microglia under the conditions of a high concentration of glutamate and chronic ocular hypertension. They assume this could be one of the plausible mechanisms that protected RGCs in experimental glaucoma. Surprisingly, 21 failed to protect the RGCs, presumably because they own long axons that have to deal with more challenges.

Vipadenant (BII014, V2006, 22), initially discovered by Juno Therapeutics and then acquired by Vernalis and Ligand Pharmaceuticals, is a selective $\mathrm{A}_{2 \mathrm{~A}} \mathrm{AR}$ antagonist developed as an oral drug for the treatment of PD (phase 2) but later discontinued due to safety concerns [74, 79]. Vipadenant was then licensed out to RedoxTherapies because of its high potential to disrupt an immunosuppressive mechanism of tumor protection [80]. When used in combination with other anticancer drugs, vipadenant is able to generate an improved efficacy for immunotherapies targeting different cancers. Vipadenant is currently in preclinical trials for cancer in the US. 
The potent and selective $\mathrm{A}_{2 \mathrm{~A}} \mathrm{AR}$ antagonist $\mathrm{SCH}-412348$ (SCH-58261, 23) has been initially identified and developed by Schering-Plough as a potential treatment for neurological conditions such as depression and PD. Given that $\mathbf{2 3}$ suffered from poor solubility and was not active when orally dosed, it has been discontinued after having completed phase 2. Starting from the observation that the blockade of $\mathrm{A}_{2 \mathrm{~A}} \mathrm{AR}$ prevents the neuroinflammatory response and can improve recovery of retinal function after exposure to elevated hydrostatic pressure (EHP), Madeira et al. investigated SCH-412348 [73, 81]. Their results showed that 23 attenuated the release of pro-inflammatory cytokines and the microglia reactivity. Moreover, it prevented ischemiareperfusion (I-R)-induced cell death resulting from the excessive raising of IOP, by attenuating the neuroinflammatory response. The authors concluded by suggesting that the blockade of $\mathrm{A}_{2 \mathrm{~A}} \mathrm{AR}$ may play an important role in the management of retinal neurodegenerative diseases such as glaucoma and ischemic diseases.

Over the last decades, academia and the pharma industry have made significant efforts toward the discovery of potent and selective $\mathrm{A}_{2 \mathrm{~A}} \mathrm{AR}$ antagonists, even if the achievement of the optimal $\mathrm{A}_{2 \mathrm{~A}} \mathrm{AR}$ antagonist with adequate physicochemical and pharmacological properties still remains a challenge.

The benzothiazole-based scaffold tozadenant (SYN-115, 24, Fig. 9), developed by Hoffmann-La Roche, represents a potent and selective $\mathrm{A}_{2 \mathrm{~A}} \mathrm{AR}$ antagonist with the desired Absorption, Distribution, Metabolism, and Excretion (ADME) properties [82, 83]. $\mathbf{2 4}$ has been then developed for the treatment of PD by the Finnish company Biotie Therapies, which was acquired by Acorda Therapeutics in 2016. At the end of 2017, Acorda Therapeutics announced that they discontinued the development of tozadenant for the treatment of PD (phase 2, NCT02453386) and liver disorders (phase 1, NCT03212313), due to serious adverse events (e.g., agranulocytosis) and safety concerns. As of yet, no preclinical or clinical studies are ongoing or have been carried out to explore the potential use of tozadenant for the treatment of glaucoma or ocular diseases.

Inspired by the scaffold of $\mathbf{2 4}$ and with the goal to discover a potent and selective series of $\mathrm{A}_{2 \mathrm{~A}} \mathrm{AR}$ antagonists with advantageous ADME properties, Basu et al. reported a new series of 2-substituted benzothiazole and thiazolo[5,4-c]pyridine derivatives [84]. Compound $\mathbf{2 5}$ emerged as a potent and selective $\mathrm{A}_{2 \mathrm{~A}} \mathrm{AR}$ antagonist with desirable drug-like properties (e.g., high oral bioavailability), making it a promising drug candidate for treating PD, cancer, and ocular diseases.

To sum up, $\mathrm{A}_{2 \mathrm{~A}} \mathrm{AR}$ agonists and antagonists showed multiple activities which seem to be in conflict with each other, and the current evidence that $\mathrm{A}_{2 \mathrm{~A}} \mathrm{AR}$ agonists may be useful on the management of glaucoma is not yet convincing.

\section{$A_{2 B} A R$ agonists and antagonists}

The $\mathrm{A}_{2 \mathrm{~B}} \mathrm{AR}$ has been cloned in 1992, and among the 4 adenosine subtypes remains the least studied, mostly because few selective ligands are available [85].

The evidence of $\mathrm{A}_{2 \mathrm{~B}} \mathrm{AR}$ in the anterior ocular segment of bovine corneal endothelium has been for the first time reported by Blazynski, highlighting that $\mathrm{A}_{2 \mathrm{~B}} \mathrm{AR}$ is present and functional in the retina [86]. Subsequently, other researchers have identified the presence of $\mathrm{A}_{2 \mathrm{~B}} \mathrm{AR}$ in Müller cells and in retinal pigment epithelial cells [87, 88].

The $A_{2 B} A R$ is implicated in inflammation in several tissues (e.g., lung, kidney, and heart) and has a critical role in hypoxic conditions and brain inflammation (e.g., Alzheimer's disease) [89-92]. So far, very little is known about the role of the $A_{2 B} A R$ in the eye. What is widely recognized is that $\mathrm{A}_{2 \mathrm{~B}} \mathrm{AR}$ plays an important role in similar types of inflammation but occurring in different tissues, even though discrepancies between anti-inflammatory and proinflammatory effects have been recorded [93].

The activation of $\mathrm{A}_{2 \mathrm{~B}} \mathrm{AR}$ by adenosine in retinal endothelial cells triggers the extracellular ERK pathway and boosts the levels of VEGF under hypoxic conditions $[94,95]$. Considering that $A_{2 B} A R$ is expressed in human RPE, its activation resulted in the inhibition of phagocytosis of outer photoreceptor segments [96]. On the other hand, the advantages or disadvantages of blocking $\mathrm{A}_{2 \mathrm{~B}} \mathrm{AR}$ in the eye have not yet been reported.

Since the involvement of $\mathrm{A}_{2 \mathrm{~B}} \mathrm{AR}$ in neuroinflammation is starting to be uncovered, it is reasonable to assume that in the next years, the role of $\mathrm{A}_{2 \mathrm{~B}} \mathrm{AR}$ in the retina under pathological conditions will be better explained. Such a new scenario will open up the opportunity to explore different therapeutic options based on $\mathrm{A}_{2 \mathrm{~B}} \mathrm{AR}$ ligands.

\section{$A_{3} A R$ agonists}

$\mathrm{A}_{3} \mathrm{AR}$ is the last receptor to be cloned [97] and is involved in a variety of different intracellular signaling pathways, ranging from inositol triphosphate (IP3), intracellular calcium $\left(\mathrm{Ca}^{+2}\right)$, and $\mathrm{Gq}$ protein coupling activating phospholipase $\mathrm{C}$ (PLC), or inhibition of AC activity through Gi coupling [98]. The pioneering studies conducted in the retina did not detect the presence of $\mathrm{A}_{3} \mathrm{AR}$, but subsequently, the receptor has been identified in the RGCs. Then Beach et al. confirmed the presence of $\mathrm{A}_{3} \mathrm{AR}$ in RPE, RGCs, and nerve fiber layer (NFL) by investigating the distribution of ARs in the retina of Rhesus monkeys [29]. Recently has emerged the role of $\mathrm{A}_{3} \mathrm{AR}$ as a modulator of inflammation, thus making it an appealing target for treating inflammatory diseases (e.g., osteoarthritis) [99]. Regarding ocular inflammation, $\mathrm{A}_{3} \mathrm{AR}$ agonists have received much attention to treating DE syndrome and uveitis [100]. Even 
Fig. 10 Chemical structures of IB-MECA (CF101, 26), Cl-IBMECA (CF102, 27), MRS-3558 (28), and MRS-3630 (29)

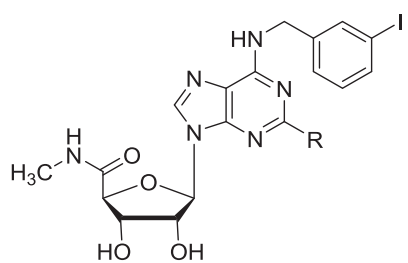

26 IB-MECA (CF101) $\mathrm{R}=\mathrm{H}$ $27 \mathrm{Cl}$-IB-MECA (CF102) $\mathrm{R}=\mathrm{Cl}$

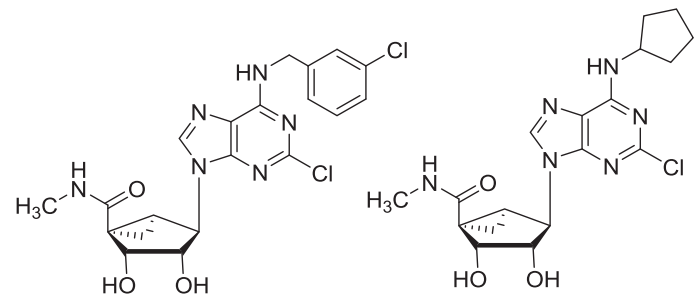

28 MRS-3558

29 MRS-3630 the influence of $\mathrm{A}_{3} \mathrm{AR}$ activation on glaucoma, $\mathrm{DR}$, and ischemic diseases has been extensively surveyed. The damage to the NFL surrounding RGCs, followed by RGC apoptotic death induced by the ATP-gated P2X7R ion channel activation, is the main feature of DR and glaucoma [101]. In chronic glaucoma, ATP is released from astrocytes of the optic nerve and triggered P2X7R resulting in apoptotic cell death of RGCs in the retina [19]. During homeostasis perturbation, cells release ATP that acts as an inflammasome activator, leading to pro-inflammatory mediators' release. Elevated ATP levels have been found in different animal models of glaucoma, and in the retina, ATP is released by Müller cells, astrocytes, and microglia. As reported by $\mathrm{Lu}$ et al., in the extracellular environment, ATP can interact with P2XRs or be hydrolyzed into adenosine by the enzymatic activity of ecto-nucleoside triphosphate diphosphohydrolases (NTPDases) [102]. An unbalanced activity of NTPDase-1, might convert more ATP into adenosine, increasing the chance of activating ARs. Indeed, Rodriguez-Neves et al. reported that in the experimental models of glaucoma, the adenosine levels are highly enhanced [103].

A readily checked risk factor of glaucoma is considered to be the elevated IOP, which is believed to be the result of reduced $\mathrm{AH}$ outflow from the anterior segment. However, the role of $\mathrm{A}_{3} \mathrm{AR}$ on lowering/increasing IOP is still controversial. It is well documented that the treatment with $\mathrm{A}_{3} \mathrm{AR}$ antagonists reduced IOP in mice as well as in $\mathrm{A}_{3} \mathrm{AR}$ knockout mice experimental models, but not all reported studies on $\mathrm{A}_{3} \mathrm{AR}$ converge on the same conclusions [25, 104, 105]. For example, the case of IB-MECA (CF101, piclodenoson, 26, Fig. 10), an $\mathrm{A}_{3} \mathrm{AR}$ agonist, is emblematic because, during the clinical trials for the treatment of $\mathrm{DE}$ syndrome, it has been found to lower IOP [106]. This surprising result could be due to unintentional crossactivation of $\mathrm{A}_{1} \mathrm{AR}$ [107] or be linked to the chronic administration of $\mathbf{2 6}$ that led to lower IOP via the pharmacological mechanism known as "effect inversion" already seen for other ARs ligands and theorized by Jacobson et al. [108].

The "inversion effect" can better clarify why the pharmacological effect of an AR ligand administered in acute can be entirely reversed if it is administered chronically
[109]. Since glaucoma therapy is administered chronically, the "inversion effect" should be considered when deciding to undertake a trial that involves AR ligands.

The activation of $\mathrm{A}_{3} \mathrm{AR}$ preserves RGC cells and restrains the rise in calcium levels caused by the stimulation of glutamate receptors [110]. In glaucoma and DR, the overactivation of glutamate receptors is responsible for raising of intracellular calcium concentration, which consequently ends up in cell death. Since RGCs express $A_{3} A R$, the protective effect may rise up from the direct action of an $\mathrm{A}_{3} \mathrm{AR}$ agonist with those cells [88]. Galvao et al. showed that $\mathrm{A}_{3} \mathrm{AR}$ activation lowered the retinal apoptotic cell death and boosted the RGC survival rate [111]. In addition, the same authors reported that the activation of $\mathrm{A}_{3} \mathrm{AR}$ preserves the retina from retinal ischemia-reperfusion (I-R) injury, from damage induced by partial optic nerve transection, and excitotoxic-induced cell death.

26 is an orally bioavailable small molecule with a favorable therapeutic index, which is being tested in several phase 2 studies by the Israeli biopharmaceutical company Can-Fite (NCT00349466 and NCT01235234). In a phase 2 study completed in 2011 to treat plaque psoriasis, 26 successfully met all its endpoints, significantly improving the disease symptoms (NCT00428974). In a phase 2/3 study the data showed a significant clinical activity from week 16 up to 32 with the $2 \mathrm{mg}$ dose daily (NCT01265667) [112], and in 2018 it entered a phase 3 study for the treatment of moderate-to-severe psoriasis (NCT03168256). Similarly, phase 2 studies demonstrated the efficacy of $\mathbf{2 6}$ given as a monotherapy for the treatment of rheumatoid arthritis. A phase 3 study is still active and is aimed to compare $\mathbf{2 6}$ to methotrexate as a first-line treatment of rheumatoid arthritis (NCT02647762).

During an early unsuccessful trial of $\mathbf{2 6}$ for DE syndrome (NCT01235234), researchers from OphthaliX, a subsidiary company of Can-Fite, have noted a modest reduction of IOP in patients obtaining the drug. The IOP reduction was further investigated and was found to be $0.92 \mathrm{mmHg}$ at a dose of $1 \mathrm{mg}$ of $\mathbf{2 6}$ twice daily [106]. Then OphthaliX conducted a phase 2 safety and efficacy clinical trial of orally administered 26 in patients with elevated IOP and glaucoma (NCT01033422) [113]. Unfortunately, during the 16 weeks of treatment with $\mathbf{2 6}$ (1 or $2 \mathrm{mg}$ twice daily) of patients with 
Fig. 11 Chemical structures of P2X7R antagonists MRS-2540 (30), and JNJ-47965567 (31)

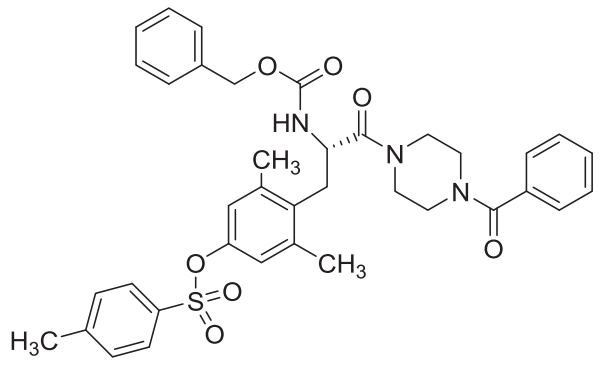

30 MRS-2540<smiles>O=C(NCC1(N2CCN(c3ccccc3)CC2)CCOCC1)c1cccnc1Sc1ccccc1</smiles>

31 JNJ-47965567 elevated IOP, no statistically significant differences were found between the placebo group and drug-treated group in the primary endpoint of lowering IOP.

Considering that $\mathbf{2 6}$ failed to meet its primary endpoint, OphthaliX has declared that they do not see any immediate path forward in glaucoma. The mechanistic limitation of using $\mathrm{A}_{3} \mathrm{AR}$ agonists to treat glaucoma may lie in the desensitization of ARs. For this reason, nucleoside prodrugs of $\mathrm{A}_{3} \mathrm{AR}$ agonists have been explored for their action on lowering IOP [114, 115].

26 also induced an anti-inflammatory effect in experimental autoimmune uveitis induced by retinal antigen interphotoreceptor retinoid-binding protein [116]. A phase 2 study to assess the safety and efficacy of $\mathbf{2 6}$ to subjects with uveitis has been planned in 2013 (NCT01905124), but later Can-Fite decided to withdraw.

Given that $\mathbf{2 6}$ has a full-blown anti-viral effect already protected by a US patent (US7589075), Can-Fite, in collaboration with the Lewis Katz School of Medicine at Temple University (Philadelphia), has recently started a study on the anti-viral activity of $\mathbf{2 6}$ on COVID-19 viral load. At the beginning of September 2020, Can-Fite received approval from the US FDA for use $\mathbf{2 6}$ in a phase 2 study to treat COVID-19 patients with moderate symptoms (NCT04333472).

Cl-IB-MECA (CF102, namodenoson, 27, Fig. 10), has been initially originated in the laboratory of Prof. Kenneth A. Jacobson at the National Institute of Diabetes and Digestive and Kidney Diseases (NIDDK), and then developed by Can-Fite for the treatment of liver conditions, such as nonalcoholic steatohepatitis (NASH) and hepatocellular carcinoma (HCC) [117]. The safety of 27 has been extensively demonstrated in several preclinical studies and in phase $1 / 2$ clinical studies, proving to be safe and effective (NCT00790218 and NCT02927314). In 2012, 27 has achieved the orphan drug status from the FDA for the treatment of HCC [118]. 27 is currently available in Israel to treat liver cancer patients through compassionate use when all available treatment options have been exhausted. CanFite has recently reached an agreement with the FDA and
EMA to begin a more extensive phase 3 clinical trial to treat liver cancer.

Elevation of IOP induces impairment and apoptotic death of RGCs, and $\mathrm{A}_{3} \mathrm{AR}$ agonists such as 27 and MRS3558 (28, Fig. 10) preserve RGCs from apoptosis induced by P2X7R activation (e.g., ATP or other nucleotides). The P2X7R overexpression in RGCs is tied with other factors (e.g., increased MAPK and caspase-3 proteins in the retina), implying a pro-apoptotic mechanism in RGC death induced by elevated IOP. Recently, Sakamoto et al. reported that $\mathrm{P} 2 \mathrm{X} 7 \mathrm{R}$ activation is involved in the mechanism of NMDA-induced retinal injury, leading to glaucomatous RGC loss [119]. The treatment with 27 decreased the number of cells encountering apoptosis and, at the same time, enhancing the RGCs survival [111]. This work has proven for the first time that 27 is neuroprotective to the retina. A dual $\mathrm{A}_{1} / \mathrm{A}_{3}$ agonist, MRS-3630 (29, Fig. 10), was also efficacious in protecting RGCs from cell death [19].

On the other hand, the treatment with P2X7R antagonists, such as MRS-2540 (30, Fig. 11) and JNJ-47965567 (31), prevents neuronal apoptosis in the retina induced by hypoxia or ATP [101, 120].

\section{$A_{3} A R$ antagonists}

As stated before, $\mathrm{A}_{3} \mathrm{AR}$ has a pivotal role in IOP regulation, even though there are concerns about agonists and antagonists of $\mathrm{A}_{3} \mathrm{AR}$ that might be useful in treating the same pathologic conditions (e.g., glaucoma). Usually, topically applied $\mathrm{A}_{3} \mathrm{AR}$ agonists increased IOP, whereas $\mathrm{A}_{3} \mathrm{AR}$ antagonists decreased IOP in mice. The selective activation of $\mathrm{A}_{3} \mathrm{AR}$ can increase $\mathrm{AH}$, and consequently increase IOP, by a mechanism that involves the activation of $\mathrm{Cl}^{-}$channels in the non-pigmented ciliary epithelial (NPE) cells [121, 122]. Studies on $\mathrm{A}_{3} \mathrm{AR}$ knockout mice have corroborated this observation. Avila et al. reported that the baseline IOP in $\mathrm{A}_{3} \mathrm{AR}$ knockout mice was significantly lower than that in wild-type ones, and $\mathrm{A}_{3} \mathrm{AR}$ agonists or antagonists did not affect at all IOP [105]. 
Fig. 12 Chemical structures of $\mathrm{A}_{3} \mathrm{AR}$ antagonists 32-41<smiles>CCOC(=O)C1=C(C)NC(c2ccccc2)=C(C(=O)OCC)C1/C=C/c1ccccc1</smiles>

32 MRS-1097<smiles>CCOC(=O)C1=C(C)NC(c2ccccc2)=C(C(=O)OCc2ccccc2)C1C#Cc1ccccc1</smiles>

33 MRS-1191<smiles>O=C(Cc1ccccc1)Nc1nc2ccc(Cl)cc2c2nc(-c3ccco3)nn12</smiles>

34 MRS-1220<smiles>CCCOC(=O)c1c(-c2ccccc2)nc(CC)c(C(=O)SCC)c1CCC</smiles>

35 MRS-1523

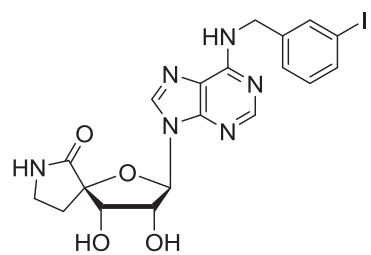

36 MRS-1292

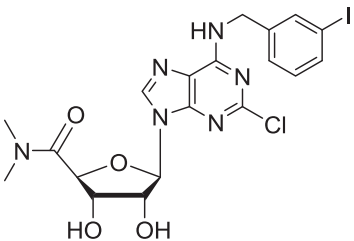

37 MRS-3771

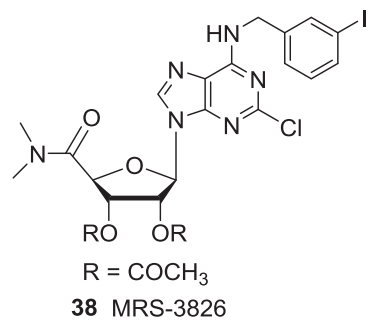

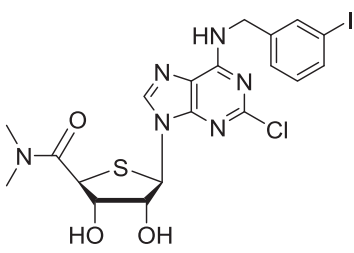

39 LJ-979

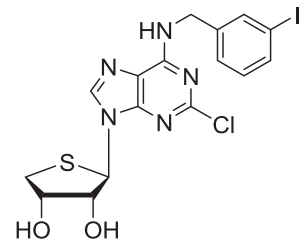

40 LJ-1251

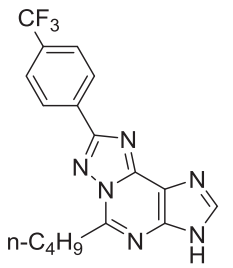

41 OT-7999
As a reasonable interconnection to clinical glaucoma, $\mathrm{A}_{3} \mathrm{AR}$ is upregulated by an order of magnitude in the nonpigmented ciliary epithelium in the pseudoexfoliation syndrome, the largest cause of secondary open-angle glaucoma. Considering the ability of the $\mathrm{A}_{3} \mathrm{AR}$ to act as a regulator of chloride transport in epithelial cells, its upregulation may have an additional influence on $\mathrm{AH}$ secretion and hence on increasing IOP [123]. This finding has opened the way to the development of selective $\mathrm{A}_{3} \mathrm{AR}$ antagonists for the treatment of glaucoma. To date, the $\mathrm{A}_{3} \mathrm{AR}$ antagonists tested for their effects on lowering IOP consisted of: the 6-phenyl-1,4-dihydropyridine derivatives MRS-1097 (32, Fig. 12) and MRS-1191 (33), the nonxanthine heterocyclic derivative MRS-1220 (34), the pyridine derivative MRS 1523 (35), the nucleoside-based antagonists MRS-1292 (36), MRS-3771 (37), MRS3826 (38), LJ-979 (39), and LJ-
1251 (40), the triazolopurine derivative OT-7999 (41), PBF-677 (structure not disclosed), and ACN-1052 (structure not disclosed).

Civan et al. [124], have patented compounds 32-35 as part of a method aimed to decrease IOP by administrating an $\mathrm{A}_{3} \mathrm{AR}$ antagonist. As reported before, adenosine and $\mathrm{A}_{3} \mathrm{AR}$ agonists cause isotonic cell shrinkage by activating $\mathrm{Cl}^{-}$channels in the basolateral membranes of NPE cells, accelerating the rate of $\mathrm{AH}$ formation and increasing IOP. $\mathrm{A}_{3} \mathrm{AR}$ antagonists such as $\mathbf{3 2 - 3 5}$ prevent $\mathrm{Cl}^{-}$outflow and decrease AH production in NPE cells [125].

The IOP responses to $\mathrm{A}_{3} \mathrm{AR}$ antagonists were monitored in $\mathrm{A}_{3}$-knockout $\left(\mathrm{A}_{3} \mathrm{AR}^{-} /^{-}\right)$and control mice $\left(\mathrm{A}_{3} \mathrm{AR}^{+} /^{+}\right)$[105]. The highly selective $\mathrm{A}_{3} \mathrm{AR}$ antagonist 33 did not impact IOP in $\mathrm{A}_{3}$-knockout mice but lowered it in control mice (by $7.0 \pm 0.9 \mathrm{mmHg}$ ). Instead, 35, 
structurally different to $\mathbf{3 3}$, reduced baseline IOP in $\mathrm{A}_{3}$ knockout mice by $3.6 \pm 0.6 \mathrm{mmHg}$, but reduced the IOP in the control mice to a more considerable extent (by $9.8 \pm$ $1.1 \mathrm{mmHg}$ ). Such a phenomenon might be explained by the relative selectivity of $\mathbf{3 5}$ for $\mathrm{A}_{3} \mathrm{ARs}$ over $\mathrm{A}_{2 \mathrm{~A}} \mathrm{AR}$ with respect to $\mathbf{3 3}$, which raises the possibility that $\mathbf{3 3}$ may have cross-occupied $\mathrm{A}_{2 \mathrm{~A}} \mathrm{AR}$, leading to a decrease of IOP.

Investigation of $\mathrm{A}_{3} \mathrm{AR}$ antagonists has often been limited by their species variability, whereas $\mathrm{A}_{3} \mathrm{AR}$ agonists usually display high affinity across species. This problem has been brilliantly overcome by modifying the highly specific, cross-species agonist IB-MECA, providing a pool of $\mathrm{A}_{3} \mathrm{AR}$ antagonists (compounds 36-40) able to act across species.

The conformationally constrained ligand MRS-1292 (36, Fig. 12), a selective $A_{3} A R$ antagonist in both the human and the rat, reduces mouse IOP and inhibits $\mathrm{A}_{3} \mathrm{AR}$-mediated shrinkage of cultured human NPE cells [104]. When applied topically, 36 generates a maximum reduction in IOP of $4.4 \pm 0.8 \mathrm{mmHg}$, making it a drug of choice for additional animal testing to fully understand the role of $\mathrm{A}_{3} \mathrm{AR}$ in increasing/decreasing IOP.

Of the four $\mathrm{A}_{3} \mathrm{AR}$ antagonists (37-40) studied by Wang et al., obtained after modification of Cl-IB-MECA (27), all of them reduced measured IOP after topical administration (Wang et al., 2010). The $4 \mathrm{~A}_{3} \mathrm{AR}$ antagonists' effect on mouse IOP was measured in two different manners: invasively (by the Servo-Null Micropipette System, SNMS) and non-invasively (by Pneumotonometry). The measurements of IOP by SNMS tonometry demonstrate the functional efficacy of 37-40 in the mouse, whereas their effect on the adenosine-triggered shrinkage of native bovine NPE cells showed that the antagonists are efficacious against bovine, as well as human and mouse $\mathrm{A}_{3} \mathrm{ARs}$.

The $5^{\prime}-N, N$-dimethyluronamide derivative MRS-3771 (37) [126] reduced IOP of $3.0 \pm 1.1 \mathrm{mmHg}$ and significantly inhibited adenosine-produced cell shrinkage of native bovine NPE, monitored by measuring cell area [127, 128].

The di-acetyl ester derivative of MRS-3771 (37), MRS3826 (38) [115], lowered IOP measured by invasively SNMS tonometry of $4.0 \pm 0.8 \mathrm{mmHg}$, but not reduced IOP measured by pneumotonome.

LJ-979 (39), an analog of Cl-IB-MECA (27) obtained by concomitant addition of a methyl group to the 5 -uronamide and $4^{\prime}$-thio substitution, reduced invasive-measured IOP of $4.2 \pm 1.2 \mathrm{mmHg}$ at a concentration of $250 \mu \mathrm{M}$.

The only tested nucleoside-based derivative that lowered IOP at a concentration of $250 \mu \mathrm{M}$ by SNMS tonometry $(1.5 \pm 0.6 \mathrm{mmHg})$ as well as by pneumotonometry $(4.2 \pm$ $0.7 \mathrm{mmHg}$ ) has been LJ-1251 (40) [129]. 40 has been synthesized starting from $\mathbf{3 9}$ by removing the $5^{\prime}$-uronamide moiety, with the aim to eliminate $\mathrm{H}$-bonding at that position. Its moderate hydrophobicity ( $\log P=2.25)$ allowed it to permeate the cornea remarkably quickly, although the underlying mechanism is still unknown and requires further study.

The triazolopurine derivative OT-7999 (41, Fig. 12), developed by Otsuka Pharmaceutical (Japan), has been studied to treat glaucoma. $\mathbf{4 1}$ was applied topically to one eye in cynomolgus monkeys with normal IOP. The results indicated that $\mathbf{4 1}$ lowered IOP of $2-3 \mathrm{mmHg}$ after 2 and 4 hours of topical application, and no ophthalmologic side effects had been detected $[24,130]$.

PBF-677 (structure not disclosed), a selective and potent gastrointestinal (GI)-restricted $\mathrm{A}_{3} \mathrm{AR}$ antagonist, has been developed by Palobiofarma, a Spanish biotechnology company, and has recently positively completed a "first in human" phase 1 study to assess safety and tolerability in healthy volunteers (NCT02639975). The drug is intended to treat glaucoma, ocular hypertension, and eye diseases and has already received the Spanish Regulatory Agency's approval.

PBF-677 is also in development as a "first-in-class" oral treatment for inflammatory bowel and is currently ongoing a proof of concept (POC) phase 2 study for assessing safety and efficacy in ulcerative colitis patients (NCT03773952).

Acorn Biomedical has suggested using ACN-1052 (structure not disclosed) for glaucoma treatment. ACN1052 is an orally bioavailable $\mathrm{A}_{3} \mathrm{AR}$ antagonist with a single-digit (nM) affinity for both the rat and human $\mathrm{A}_{3} \mathrm{AR}$. Its pharmacodynamics has been extensively studied in preclinical models. ACN-1052 reduced IOP after topical administration, and with a chronic administration, it generated a prolonged effect in reducing IOP. It is worth noting to mention that the IOP reduction obtained with ACN-1052 is 2-fold lower than that obtained with first-line drugs such as brimonidine tartrate (Alphagan ${ }^{\circ}$ ) or latanoprost (Xalatan ${ }^{\circ}$ ).

Summing up, it should be pointed out that all tested $\mathrm{A}_{3} \mathrm{AR}$ antagonists are in the preclinical stage, except for PBF-677 [113].

\section{$A_{1} A R$ agonists $/ A_{3} A R$ antagonists}

Given the wide distribution of AR subtypes in all mammal tissues, an innovative strategy that allows avoiding the side effects represents a good starting point for selective AR ligands' therapeutic development. For this reason, the emerging and alternative approach, called polypharmacology, has been gaining increasing attention in the last decade. Polypharmacology consists of modulating multiple targets related to only one disease pathway with a single drug. In this respect, a drug that hits multiple sensitive targets (multitarget drug) offers the potential for higher efficacy and curtails drawbacks that generally arise from the use of combination therapies [131, 132]. Furthermore, a 


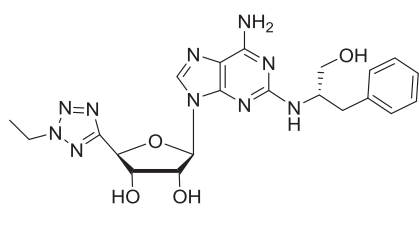

$42 \mathrm{GW} 328276 \mathrm{X}$

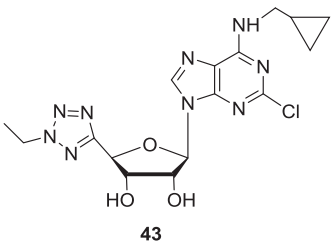

Fig. 13 Chemical structures of GW328276X (42) and 43

multitarget drug has the benefit of following only one metabolic pattern and pharmacokinetic, which instead represent a significant constraint of the combination therapy.

In the AR arena, several examples of dual-acting ligands have been reported. $\mathrm{A}$ dual $\mathrm{A}_{2 \mathrm{~A}} \mathrm{AR}$ agonist and $\mathrm{A}_{3} \mathrm{AR}$ antagonist, called GW328267X (42, Fig. 13), has been designed by Glaxo as an anti-inflammatory agent [133]. Despite its full-blown anti-inflammatory efficacy in animal models, 42 failed to show efficacy in a clinical trial for allergic rhinitis and asthma (NCT01640990). Side effects directly linked to its agonist activity at $\mathrm{A}_{1} \mathrm{AR}$ (i.e., tachycardia and hypotension) have limited its clinical development. Later on, Hou et al. synthesized a new series of dualacting $h \mathrm{~A}_{2} \mathrm{AR}$ agonists and $h \mathrm{~A}_{3} \mathrm{AR}$ antagonists with the aim to be developed for the treatment of asthma and inflammatory diseases [134]. Recently, Jacobson et al. have hypothesized that a dual $\mathrm{A}_{1} \mathrm{AR}$ antagonist and $\mathrm{A}_{2 \mathrm{~A}} \mathrm{AR}$ agonist may have a beneficial impact on the treatment of asthma [135].

By relying on the dual-acting ligand approach, in 2015, we reported the first highly potent dual-acting $h \mathrm{~A}_{1} \mathrm{AR}$ agonists and $h \mathrm{~A}_{3} \mathrm{AR}$ antagonists [136]. Combining a 5'-Cethyltetrazol-2-yl moiety with the appropriate $N^{6}$-substitution in adenosine derivatives, an increased affinity versus both $h \mathrm{~A}_{1} \mathrm{AR}$ and $h \mathrm{~A}_{3} \mathrm{AR}$ (at the subnanomolar range) was achieved while remaining agonists at $h \mathrm{~A}_{1} \mathrm{AR}$ and antagonists at $h \mathrm{~A}_{3} \mathrm{AR}$. The follow-up paper aimed to extend the series of 5'-C-(ethyltetrazol-2-yl)adenosine and 2chloroadenosine derivatives, modifying the substituent in the $N^{6}$-position of the adenine ring [137]. This study demonstrated for the first time that all dual-acting $N^{6}$-substituted 5'-C-ethyl-tetrazolyl adenosine derivatives act as antagonists at human $\mathrm{A}_{3} \mathrm{AR}$ but as agonists at the rat $\mathrm{A}_{3} \mathrm{AR}$, highlighting the importance of species differences for both affinity and efficacy at $\mathrm{A}_{3} \mathrm{AR}$. Additionally, this new series has allowed us to disclose $N^{6}$-cyclopropylmethyl-5'-C(ethyltetrazol-2-yl)-2-chloroadenosine (43), a very potent dual-acting $\mathrm{A}_{1} / \mathrm{A}_{3}$ agonist in rat and $\mathrm{A}_{1} \mathrm{AR}$ agonist/ $\mathrm{A}_{3} \mathrm{AR}$ antagonist in human ARs.

Moreover, this new series of compounds may represent a set of pharmacological tools for in vivo studies with the aim of investigating the advantages of dual-acting $\mathrm{A}_{1} \mathrm{AR}$ agonists and $\mathrm{A}_{3} \mathrm{AR}$ antagonists in several diseases. A single molecule with one pharmacokinetic profile, activating one signaling pathway while blocking another one, could potentially be a promising candidate to reduce elevated IOP and have the capability to be used in the treatment of glaucoma.

This approach had previously been attempted by Inotek Pharmaceuticals, who have patented the use of combination therapy based on an $\mathrm{A}_{1} \mathrm{AR}$ agonist (i.e., trabodenoson) and an $\mathrm{A}_{3} \mathrm{AR}$ antagonist for the treatment of diseases and conditions caused by elevated IOP [138]. The results of the in vivo administration of the combination therapy showed a substantial decrease in IOP during the entire observation period $(\sim 6 \mathrm{~h})$.

\section{Conclusions}

In the past two decades, a significant medicinal chemistry campaign around the ARs in the ocular therapeutic field has been conducted. The activation or blockage of ARs is involved in the modulation of IOP, retinal function, $\mathrm{AH}$ formation, neuroprotection, and blood flow. Data from preclinical and clinical trials are extremely encouraging and shed some light on the role of ARs in ocular diseases. Although it has been highlighted a puzzling and contradictory scenario of modulation of purinoma in the eye, the ARs ligands hold promise for future ocular therapeutics. However, a better understanding of their exact contribution to glaucoma or other ocular diseases is a crucial step in order to future design new therapeutics built on ARs agonists or antagonists.

Acknowledgements The authors (LC and RP) thank the University of Camerino (Fondo di Ateneo per la Ricerca, FAR 2018) and the PRIN grant from the Italian Ministry of Health to R.P. (PRIN 2017CBNCYT_005) for the financial support.

\section{Compliance with ethical standards}

Conflict of interest The authors declare that they have no conflict of interest.

Publisher's note Springer Nature remains neutral with regard to jurisdictional claims in published maps and institutional affiliations.

\section{References}

1. World Health Organization (WHO) (2020). Blindness-andvisual-impairment. https://www.who.int/news-room/fact-sheets/ detail/blindness-and-visual-impairment Accessed 12 October 2020.

2. Adams CM, Papillon JPN (2020). Recent Developments for the Treatment of Glaucoma. In: Topics in medicinal chemistry. Berlin, Heidelberg: Springer. https://doi.org/10.1007/7355_ 2019_92. 
3. Quigley HA, Broman A. The number of people with glaucoma worldwide in 2010 and 2020. Br J Ophthalmol. 2006;90:262-7.

4. Aires ID, Ambrosio AF, Santiago AR. Modeling human glaucoma: Lessons from the in vitro models. Ophthalmic Res. 2017;57:77-86.

5. Tham YC, Li X, Wong TY, Quigley HA, Aung T, Cheng CY. Global prevalence of glaucoma and projections of glaucoma burden through 2040: a systematic review and meta-analysis. Ophthalmology. 2014;121:2081-90.

6. Hood DC. Improving our understanding, and detection, of glaucomatous damage: An approach based upon optical coherence tomography (OCT). Prog Retin Eye Res. 2017;57:46-75.

7. Xin C, Wang RK, Song $S$, Shen $T$, Wen J, üartin $E$, et al. Aqueous outflow regulation: Optical coherence tomography implicates pressure-dependent tissue motion. Exp Eye Res. 2017;158:171-86.

8. Heijl A, Leske MC, Bengtsson B, Hyman L, Bengtsson B, Hussein M. Reduction of intraocular pressure and glaucoma progression: results from the Early Manifest Glaucoma Trial. Arch Ophthalmol. 2002;120:1268-79.

9. Kish T. Old and new drug classes expanding to include glaucoma treatments. Pharm Ther. 2018;43:489.

10. Mehran NA, Sinha S, Razeghinejad R. New glaucoma medications: latanoprostene bunod, netarsudil, and fixed combination netarsudil-latanoprost. Eye. 2020;34:72-88.

11. Findlay Q, Reid K. Dry eye disease: when to treat and when to refer. Aust Prescr. 2018;41:160-3.

12. Madeira MH, Boia R, Santos PF, Ambrosio AF, Santiago AR. Contribution of microglia-mediated neuroinflammation to retinal degenerative diseases. Mediat Inflamm. 2015;2015:673090.

13. Aires ID, Boia R, Rodrigues-Neves AC, Madeira MH, Marques $\mathrm{C}$, Ambrosio AF, et al. Blockade of microglial adenosine A2A receptor suppresses elevated pressure-induced inflammation, oxidative stress, and cell death in retinal cells. Glia. 2019;67:896-914.

14. Chou R, Dana T, Bougatsos C, Grusing S, Blazina I. Screening for impaired visual acuity in older adults: updated evidence report and systematic review for the U.S. Preventive Services Task Force. JAMA. 2016;315:915-33.

15. Bonilha VL. Age and disease-related structural changes in the retinal pigment epithelium. Clin Ophthalmol. 2008;2:413-24.

16. Royal National Institute of Blind People: London (2020). AntiVEGF Treatment https://www.rnib.org.uk/eye-health/eyeconditions/anti-vegf-treatment Accessed October 152020.

17. Duh EJ, Sun JK, Stitt AW. Diabetic retinopathy: current understanding, mechanisms, and treatment strategies. JCI Insight. 2017;2:e93751.

18. Cheng KJ, Hsieh CM, Nepali K, Liou JP. Ocular disease therapeutics: design and delivery of drugs for diseases of the eye. $\mathrm{J}$ Med Chem. 2020;63:10533-93.

19. Jacobson KA, Civan MM. Ocular purine receptors as drug targets in the eye. J Ocul Pharm Ther. 2016a;32:534-47.

20. Jacobson KA, Müller CE. Medicinal chemistry of adenosine, P2Y and P2X receptors. Neuropharmacology. 2016b;104:31-49.

21. Rich CC, Albers DS, Gow JA, Baumgartner RA, Samples JR, Knepper P. Targeting the adenosine A1 receptor in the eye with trabodenoson, an adenosine mimetic. Glauc Res Clin Adv. 2018;33:237-52.

22. Fishman P, Cohen S, Bar-Yehuda S. Targeting the A3 adenosine receptor for glaucoma treatment. Mol Med Rep. 2013;7:1723-5.

23. Jacobson KA, Tosh DK, Jain S, Gao ZG. Historical and current adenosine receptor agonists in preclinical and clinical development. Front Cell Neurosci. 2019;13:124-41.

24. Jacobson KA, Klutz AM, Tosh DK, Ivanov AA, Preti D, Baraldi PG. Medicinal chemistry of the A3 adenosine receptor: agonists, antagonists, and receptor engineering. Handb Exp Pharm. 2009;193:123-59.

25. Zhong Y, Yang Z, Huang WC, Luo X. Adenosine, adenosine receptors and glaucoma: an updated overview. Biochim Biophys Acta. 2013;1830:2882-90.

26. Daines BS, Kent AR, McAleer MS, Crosson CE. Intraocular adenosine levels in normal and ocular hypertensive patients. J Ocul Pharm Ther. 2003;19:113-9.

27. Santiago AR, Madeira MH, Boia R, Aires ID, Rodrigues-Neves $\mathrm{C}$, Santos PF, et al. Keep an eye on adenosine: Its role in retinal inflammation. Pharmacol Ther. 2020:210;107513.

28. Lynge J, Hellsten Y. Distribution of adenosine A1, A2A and A2B receptors in human skeletal muscle. Acta Physiol Scand. 2000;169:283.

29. Beach KM, Hung LF, Arumugam B, Smit EL, Ostrin LA. Adenosine receptor distribution in rhesus monkey ocular tissue. Exp Eye Res. 2018;174:40-50.

30. Pedata F, Dettori I, Coppi E, Melani A, Fusco I, Corradetti R, et al. Purinergic signalling in brain ischemia. Neuropharmacology. 2016;104:105-30.

31. Shearer TW, Crosson CE. Adenosine A1 receptor modulation of MMP-2 secretion by trabecular meshwork cells. Invest Ophth Vis Sci. 2002;43:3016-20.

32. Li A, Leung CT, Peterson-Yantorno K, Stamer WD, Mitchell $\mathrm{CH}$, Civan MM. Mechanisms of ATP release by human trabecular meshwork cells, the enabling step in purinergic regulation of aqueous humor outflow. J Cell Physiol. 2012;227:172-82.

33. Petrelli R, Grifantini M, Cappellacci L. Development of Cmethyl branched purine ribonucleoside analogs: chemistry, biological activity and therapeutic potential. Curr Med Chem. 2016;23:3118-35.

34. Petrelli R, Scortichini M, Belardo C, Boccella S, Luongo L, Capone F, et al. Structure-based design, synthesis, and in vivo antinociceptive effects of selective A1 adenosine receptor agonists. J Med Chem. 2018;61:305-18.

35. Cappellacci L, Barboni G, Palmieri M, Pasqualini M, Grifantini M, Costa B, et al. Ribose-modified nucleosides as ligands for adenosine receptors: Synthesis, conformational analysis, and biological evaluation of 1'-C-methyl adenosine analogues. J Med Chem. 2002;45:1196-202.

36. Cappellacci L, Franchetti P, Pasqualini M, Petrelli R, Vita P, Lavecchia A, et al. Synthesis, biological evaluation, and molecular modeling of ribose-modified adenosine analogues as adenosine receptor agonists. J Med Chem. 2005;48:1550-62.

37. Cappellacci L, Franchetti P, Vita P, Petrelli R, Lavecchia A, Costa B, et al. 5'-Carbamoyl derivatives of 2'-C-methyl-purine nucleosides as selective A1 adenosine receptor agonists: affinity, efficacy, and selectivity for A1 receptor from different species. Bioorg Med Chem. 2008;16:336-53.

38. Franchetti P, Cappellacci L, Marchetti S, Trincavelli L, Martini C, Mazzoni MR, et al. 2'-C-Methyl analogues of selective adenosine receptor agonists: synthesis and binding studies. J Med Chem. 1998;41:1708-15.

39. Gao ZG, Tosh DK, Jain S, Yu J, Suresh RR, Jacobson KA. A1 Adenosine receptor agonists, antagonists, and allosteric modulators. The adenosine receptors. Cham: Humana Press; 2018. pp. 59-89.

40. Maione S, de Novellis V, Cappellacci L, Palazzo E, Vita D, Luongo $\mathrm{L}$, et al. The antinociceptive effect of 2-chloro-2'-Cmethyl-N6-cyclopentyladenosine (2'-Me-CCPA), a highly selective adenosine A1 receptor agonist, in the rat. Pain. 2007;131:281-92.

41. Trivedi BK, Bridges AJ, Patt WC, Priebe SR, Bruns RF. N6Bicycloalkyladenosines with unusually high potency and selectivity for the adenosine A1 receptor. J Med Chem. 1989;32:8-11. 
42. Gao ZG, Jacobson KA. 2-Chloro-N6-cyclopentyladenosine, adenosine A1 receptor agonist, antagonizes the adenosine A3 receptor. Eur J Pharm. 2002;443:39-42.

43. Gao ZG, Blaustein J, Gross AS, Melman N, Jacobson KA. N6Substituted adenosine derivatives: selectivity, efficacy, and species differences at A3 adenosine receptors. Biochem Pharm. 2003;65:1675-84.

44. Carlin JL, Shalini J, Gizewski E, Wan TC, Tosh DK, Xiao C, et al. Hypothermia in mouse is caused by adenosine A1 and A3 receptor agonists and AMP via three distinct mechanisms. Neuropharmacology. 2017;114:101-13.

45. Franchetti P, Cappellacci L, Vita P, Petrelli R, Lavecchia A, Kachler S, et al. N6-Cycloalkyl-and N6-bicycloalkyl-C5'(C2')modified adenosine derivatives as high-affinity and selective agonists at the human A1 adenosine receptor with antinociceptive effects in mice. J Med Chem. 2009;52:2393-406.

46. Li G, Torrejon KY, Unser AM, Ahmed F, Navarro ID, Baumgartner RA, et al. Trabodenoson, an adenosine mimetic with A1 receptor selectivity, lowers intraocular pressure by increasing conventional outflow facility in mice. Invest Ophth Vis Sci. 2018;59:383-92.

47. Myers JS, Sall KN, DuBiner H, Slomowitz N, McVicar W, Rich $\mathrm{CC}$, et al. A dose-escalation study to evaluate the safety, tolerability, pharmacokinetics, and efficacy of 2 and 4 weeks of twice-daily ocular trabodenoson in adults with ocular hypertension or primary open-angle glaucoma. J Ocul Pharm Ther. 2016;32:555-62.

48. Kosmowska B, Ossowska K, Głowacka U, Wardas J. Tremorolytic effect of 5'-chloro-5'-deoxy-( \pm -ENBA, a potent and selective adenosine A1 receptor agonist, evaluated in the harmaline-induced model in rats. CNS Neurosci Ther. 2017;23:438-46.

49. Luongo L, Guida F, Imperatore R, Napolitano F, Gatta L, Cristino L, et al. The A1 adenosine receptor as a new player in microglia physiology. Glia. 2014;62:122-32.

50. Luongo L, Petrelli R, Gatta L, Giordano C, Guida F, Vita P, et al. 5'-Chloro-5'-deoxy-( \pm -) ENBA, a potent and selective adenosine A1 receptor agonist, alleviates neuropathic pain in mice through functional glial and microglial changes without affecting motor or cardiovascular functions. Molecules. 2012;17:13712-26.

51. Mango D, Bonito-Oliva A, Ledonne A, Cappellacci L, Petrelli R, Nisticò R, et al. Adenosine A1 receptor stimulation reduces D1 receptor-mediated GABAergic transmission from striatonigral terminals and attenuates L-DOPA-induced dyskinesia in dopamine-denervated mice. Exp Neurol. 2014;261:733-43.

52. Ossowska K, Kosmowska B, Wardas J. Potential antipsychotic action of the selective agonist of adenosine A1 receptors, 5'-Cl5'-deoxy-ENBA, in amphetamine and MK-801 rat models. Pharmac Rep. 2020;72:580-88.

53. Kiesman WF, Elzein E, Zablocki J. A1 Adenosine receptor antagonists, agonists, and allosteric enhancers. Handb Exp Pharm. 2009;193:25-58.

54. Dal Ben D, Lambertucci C, Buccioni M, Martí Navia A, Marucci G, Spinaci A, et al. Non-nucleoside agonists of the adenosine receptors: an overview. Pharmaceuticals. 2019;12:150.

55. Voors AA, Düngen HD, Senni M, Nodari S, Agostoni $P$, Ponikowski P, et al. Safety and tolerability of Neladenoson Bialanate, a novel oral partial adenosine A1 receptor agonist, in patients with chronic heart failure. J Clin Pharm. 2017;57: 440-51.

56. Albrecht-Küpper BE, Leineweber K, Nell PG. Partial adenosine A1 receptor agonists for cardiovascular therapies. Purinergic Signal. 2012;8:91-99.

57. Klar J, Von Degenfeld G, Lerchen HG, Albrecht-Kupper B, Knorr A, Sandner P, et al. adenosine A1 agonists for the treatment of glaucoma and ocular hypertension. WO2012/028585. 2012;8:2012. filled March
58. Baltos JA, Vecchio EA, Harris MA, Qin CX, Ritchie RH, Christopoulos A, et al. Capadenoson, a clinically trialed partial adenosine A1 receptor agonist, can stimulate adenosine A2B receptor biased agonism. Biochem Pharm. 2017;135:79-89.

59. Voors AA, Bax JJ, Hernandez AF, Wirtz AB, Pap AF, Ferreira $A C$, et al. Safety and efficacy of the partial adenosine A1 receptor agonist neladenoson bialanate in patients with chronic heart failure with reduced ejection fraction: a phase $\mathrm{IIb}$, randomized, double-blind, placebo-controlled trial. Eur J Heart Fail. 2019;21:1426-33.

60. Crosson CE. Adenosine receptor activation modulates intraocular pressure in rabbits. J Pharm Exp Ther. 1995;273:320-6.

61. Avila MY, Stone RA, Civan MM. A(1)-, A(2A)- and A(3)subtype adenosine receptors modulate intraocular pressure in the mouse. Br J Pharm. 2001;134:241-5.

62. Crosson CE, Petrovich M. Contributions of adenosine receptor activation to the ocular actions of epinephrine. Invest Ophth Vis Sci. 1999;40:2054-61.

63. Li B, Rosenbaum PS, Jennings NM, Maxwell KM, Roth S. Differing roles of adenosine receptor subtypes in retinal ischemia-reperfusion injury in the rat. Exp Eye Res. 1999;68:9-17.

64. Dos Santos-Rodrigues A, Pereira MR, Brito R, de Oliveira NA, Paes-de-Carvalho R. Adenosine transporters and receptors: Key elements for retinal function and neuroprotection. Vitam Horm. 2015;98:487-523.

65. Wurm A, Pannicke T, Iandiev I, Francke M, Hollborn M, Wiedemann $\mathrm{P}$, et al. Purinergic signaling involved in Muller cell function in the mammalian retina. Prog Retin Eye Res. 2011;30:324-42.

66. Ahmad S, Fatteh N, El-Sherbiny NM, Naime A, Ibrahim AS, ElSherbiny A, et al. Potential role of A2A adenosine receptor in traumatic optic neuropathy. J Immumol. 2013;264:54-64.

67. Konno T, Murakami A, Uchibori T, Nagai A, Kogi K, Nakahata $\mathrm{N}$. Involvement of adenosine $\mathrm{A} 2 \mathrm{~A}$ receptor in intraocular pressure decrease induced by 2-(1-octyn-1-yl)adenosine or 2-(6cyano-1-hexyn-1-yl)adenosine. J Pharm Sci. 2005;97:501-9.

68. Mantell S, Jones R, Trevethick M. Design and application of locally delivered agonists of the adenosine A2A receptor. Expert Rev Clin Pharm. 2010;3:55-72.

69. Hothersall JD, Guo D, Sarda S, Sheppard RJ, Chen H, Keur W, et al. Structure-activity relationships of the sustained effects of adenosine A2A receptor agonists driven by slow dissociation kinetics. Mol Pharm. 2017;91:25-38.

70. Donegan RK, Lieberman RL. Discovery of molecular therapeutics for glaucoma: challenges, successes, and promising directions. J Med Chem. 2016;59:788-809.

71. Levkovitch-Verbin H. Retinal ganglion cell apoptotic pathway in glaucoma: initiating and downstream mechanisms. Prog Brain Res. 2015;220:37-57.

72. Mac Nair CE, Nickells RW. Neuroinflammation in glaucoma and optic nerve damage. Prog Mol Biol Transl Sci. 2015;134: 343-63.

73. Madeira MH, Elvas F, Boia R, Gonçalves FQ, Cunha RA, Ambrósio AF, et al. Adenosine A2AR blockade prevents neuroinflammation-induced death of retinal ganglion cells caused by elevated pressure. J Neuroinflamm. 2015;12:115.

74. de Lera Ruiz M, Lim YH, Zheng J. Adenosine A2A receptor as a drug discovery target. J Med Chem. 2014;57:3623-50.

75. Boia R, Elvas F, Madeira MH, Aires ID, Rodrigues-Neves AC, Traihão $\mathrm{P}$, et al. Treatment with $\mathrm{A} 2 \mathrm{~A}$ receptor antagonist KW6002 and caffeine intake regulate microglia reactivity and protect retina against transient ischemic damage. Cell Death Dis. 2017;8:e3065.

76. Jaakola VP, Griffith MT, Hanson MA, Cherezov V, Chien EY, Lane JR, et al. The 2.6 angstrom crystal structure of a human 
A2A adenosine receptor bound to an antagonist. Science. 2008;322:1211-7.

77. Carpenter B, Lebon G. Human Adenosine A2A receptor: molecular mechanism of ligand binding and activation. Front Pharm. 2017;8:898.

78. Liu X, Huang P, Wang J, Yang Z, Huang S, Luo X, et al. The effect of A2A receptor antagonist on microglial activation in experimental glaucoma. Invest Ophth Vis Sci. 2016;57:776-86.

79. Pinna A. Novel investigational adenosine A2A receptor antagonists for Parkinson's disease. Expert Opin Invest Drugs. 2009;18:1619-31.

80. Mediavilla-Varela M, Castro J, Chiappori A, Noyes D, Hernandez DC, Allard B, et al. A Novel Antagonist of the Immune Checkpoint Protein Adenosine A2a Receptor Restores Tumor-Infiltrating Lymphocyte Activity in the Context of the Tumor Microenvironment. Neoplasia. 2017;19:530-6.

81. Madeira MH, Boia R, Elvas F, Martins T, Ambrósio AF, Santiago AR. Selective A2A receptor antagonist prevents microglia-mediated neuroinflammation and protects retinal ganglion cells from high intraocular pressure-induced transient ischemic injury. Transl Res. 2016;169:112-28.

82. Deng Q, Lim YH, Anand R, Yu Y, Kim JH, Zhou W, et al. Use of molecular modeling aided design to dial out hERG liability in adenosine A2A receptor antagonists. Bioorg Med Chem Lett. 2015;25:2958-62.

83. Flohr A, Moreau JL, Poli SM, Riemer C, Steward L. 4-Hydroxy4-methyl-piperidine-1-carboxyclic acid (4-methoxy-7-morpholin4-yl-benzothiazol-2-yl)-amide. US-20050261289. 2005;24:2005. filled November.

84. Basu S, Barawkar DA, Thorat S, Shejul YD, Patel M, Naykodi $\mathrm{M}$, et al. Design, synthesis of novel, potent, selective, orally bioavailable adenosine A2A receptor antagonists and their biological evaluation. J Med Chem. 2017;60:681-94.

85. Fredholm BB, IJzerman AP, Jacobson KA, Linden J, Muller CE. International Union of Basic and Clinical Pharmacology. LXXXI. Nomenclature and classification of adenosine receptors-an update. Pharm Rev. 2011;63:1-34.

86. Blazynski C. Characterization of adenosine A2 receptors in bovine retinal pigment epithelial membranes. Exp Eye Res. 1993;56:595-9.

87. Newman EA. Calcium increases in retinal glial cells evoked by light-induced neuronal activity. J Neurosc. 2005;25:5502-10.

88. Zhang M, Budak MT, Lu W, Khurana TS, Zhang X, Laties AM, et al. Identification of the $\mathrm{A} 3$ adenosine receptor in rat retinal ganglion cells. Mol Vis. 2006;12:937-48.

89. Merighi S, Bencivenni S, Vincenzi F, Varani K, Borea PA, Gessi S. A2B adenosine receptors stimulate IL- 6 production in primary murine microglia through p38 MAPK kinase pathway. Pharm Res. 2017;117:9-19.

90. Rosi S, McGann K, Hauss-Wegrzyniak B, Wenk GL. The influence of brain inflammation upon neuronal adenosine A2B receptors. J Neurochem. 2003;86:220-7.

91. Borea PA, Gessi S, Merighi S, Varani K. Adenosine as a multisignalling guardian angel in human diseases: When, where and how does it exert its protective effects? Trends Pharm Sci. 2016;37:419-34.

92. Gessi S, Merighi S, Stefanelli A, Fazzi D, Varani K, Borea PA. A(1) and A (3) adenosine receptors inhibit LPS-induced hypoxia-inducible factor-1 accumulation in murine astrocytes. Pharm Res. 2013;76:157-70.

93. Borea PA, Gessi S, Merighi S, Vincenzi F, Varani K. Pharmacology of adenosine receptors: the state of the art. Physiol Rev. 2018;98:1591-625.

94. Grant MB, Davis MI, Caballero S, Feoktistov I, Biaggioni I, Belardinelli L. Proliferation, migration, and ERK activation in human retinal endothelial cells through $\mathrm{A}(2 \mathrm{~B})$ adenosine receptor stimulation. Invest Ophth Vis Sci. 2001;42:2068-73.

95. Grant MB, Tarnuzzer RW, Caballero S, Ozeck MJ, Davis MI, Spoerri PE, et al. Adenosine receptor activation induces vascular endothelial growth factor in human retinal endothelial cells. Circ Res. 1999;85:699-706.

96. Gregory CY, Abrams TA, Hall MO. Stimulation of A2 adenosine receptors inhibits the ingestion of photoreceptor outer segments by retinal pigment epithelium. Invest Ophth Vis Sci. 1994;35:819-25.

97. Zhou QY, Li C, Olah ME, Johnson RA, Stiles GL, Civelli O. Molecular cloning and characterization of an adenosine receptor: the A3 adenosine receptor. Proc Natl Acad Sci USA. 1992;89:7432-6.

98. Jacobson KA, Gao Z. Adenosine receptors as therapeutic targets. Nat Rev Drug Discov. 2006;5:247-64.

99. Jacobson KA, Merighi S, Varani K, Borea P, Baraldi S, Aghazadeh Tabrizi M, et al. A3 adenosine receptors as modulators of inflammation: From medicinal chemistry to therapy. Med Res Rev. 2018;38:1031-72.

100. Weinstein JE, Pepple KL. Cytokines in uveitis. Curr Opin Ophthalmol. 2018;29:267-74.

101. Hu H, Lu W, Zhang M, Xhang X, Argall AJ, Patel S, et al. Stimulation of the P2X7 receptor kills rat retinal ganglion cells in vivo. Exp Eye Res. 2010;91:425-32.

102. Lu W, Hu H, Sevigny J, Gabelt BT, Kaufman PL, Johnson EC, et al. Rat, mouse, and primate models of chronic glaucoma show sustained elevation of extracellular ATP and altered purinergic signaling in the posterior eye. Invest Ophth Vis Sci. 2015;56:3075-83.

103. Rodrigues-Neves AC, Aires ID, Vindeirinho, Boia R, Madeira $\mathrm{MH}$, Goncalves $\mathrm{FQ}$, et al. Elevated pressure changes the purinergic system of microglial cells. Front Pharm. 2018;9:16.

104. Yang H, Avila MY, Peterson-Yantorno K, Coca-Prados M, Stone RA, Jacobson KA, et al. The cross-species A3 adenosine-receptor antagonist MRS 1292 inhibits adenosine-triggered human nonpigmented ciliary epithelial cell fluid release and reduces mouse intraocular pressure. Curr Eye Res. 2005;30:747-54.

105. Avila MY, Stone RA, Civan MM. Knockout of A3 adenosine receptors reduces mouse intraocular pressure. Invest Ophth Vis Sci. 2002;43:3021-6.

106. Avni I, Garzozi HJ, Barequet IS, Segev F, Varssano D, Sartani $\mathrm{G}$, et al. Treatment of dry eye syndrome with orally administered CF101: data from a phase 2 clinical trial. Ophthalmology. 2010;117:1287-93.

107. Müller CE, Jacobson KA. Recent developments in adenosine receptor ligands and their potential as novel drugs. Biochim Biophys Acta Biomembr. 2011;1808:1290-308.

108. Jacobson KA, von Lubitz DKJE, Daly JW, Fredholm BB. Adenosine receptor ligands: differences with acute versus chronic treatment. Trends Pharm Sci. 1996;17:108-13.

109. Bucolo C, Platania C, Drago F, Bonfiglio V, Reibaldi M, Avitabile T, et al. Novel therapeutics in glaucoma management. Curr Neuropharmacol. 2018;16:978-92.

110. Zhang M, Hu H, Zhang X, Lu W, Lim J, Eysteinsson T, et al. The A3 adenosine receptor attenuates the calcium rise triggered by NMDA receptors in retinal ganglion cells. Neurochem Int. 2010;56:35-41.

111. Galvao J, Elvas F, Martins T, Cordeiro MF, Ambrosio AF, Santiago AR. Adenosine A3 receptor activation is neuroprotective against retinal neurodegeneration. Experim Eye Res. 2015;140:74

112. Fishman P, Bar-Yehuda S, Liang BT, Jacobson KA. Pharmacological and therapeutic effects of A3 adenosine receptor (A3AR) agonists. Drug Disco Today. 2012;17:359-66. 
113. Chen J, Runyan SA, Robinson MR. Novel ocular antihypertensive compounds in clinical trials. Clin Ophthalmol. 2011;5:667-77.

114. Wang Z, Do CW, Avila MY, Stone RA, Jacobson KA, Civan MM. Barrier qualities of the mouse eye to topically applied drugs. Exp Eye Res. 2007;85:105-12.

115. Besada P, Mamedova LK, Palaniappan KK, Gao ZG, Joshi B, Jeong LS, et al. Nucleoside prodrugs of A3 adenosine receptor agonists and antagonists. Coll Czech Chem Comm. 2006;71:912-28.

116. Bar-Yehuda S, Luger D, Ochaion A, Cohen S, Patokaa R, Zozulya G, et al. Inhibition of experimental autoimmune uveitis by the A3 adenosine receptor agonist CF101. Int J Mol Med. 2011;28:727-31.

117. Fishman P, Salhab A, Cohen S, Amer J, Itzhak I, Barer F, et al. The anti-inflammatory and anto-fibrogenic effects of namodenoson in NAFLD/NASH animal models. Abstract Thu-487. J Hepatol. 2018;68:S349-S350.

118. Janes K, Esposito E, Doyle T, Cuzzocrea S, Tosh DK, Jacobson $\mathrm{KA}$, et al. A3 adenosine receptor agonist prevents the development of paclitaxel-induced neuropathic pain by modulating spinal glial-restricted redox-dependent signaling pathways. Pain. 2014;155:2560-7.

119. Sakamoto K, Endo K, Suzuki T, Fujimura K, Kurauchi Y, Mori A, et al. P2X7 receptor antagonists protect against N-methyl-Daspartic acid-induced neuronal injury in the rat retina. Eur $\mathbf{J}$ Pharm. 2015;756:52-58.

120. Mélik Parsadaniantz S, Réaux-le Goazigo A, Sapienza A, Habas C, Baudouin C. Glaucoma: a degenerative optic neuropathy related to neuroinflammation? Cells. 2020;9:535.

121. Carré DA, Mitchell CH, Peterson-Yantorno K, Coca-Prados M, Civan MM. Similarity of A3-adenosine and swelling-activated $\mathrm{Cl}-$ channels in nonpigmented ciliary epithelial cells. Am J Physiol Cell Physiol. 2000;279:C440-C451.

122. Civan MM, Macknight AD. The ins and outs of aqueous humour secretion. Exp Eye Res. 2004;78:625-31.

123. Schlotzer-Schrehardt U, Zenkel M, Decking U, Haubs D, Kruse $\mathrm{FE}$, Junemann A, et al. Selective upregulation of the A3 adenosine receptor in eyes with pseudoexfoliation syndrome and glaucoma. Invest Ophth Vis Sci. 2005;46:2023-34.

124. Civan MM, Stone RA, Mitchell CH, Jacobson KA. Methods for reducing intraocular pressure using $\mathrm{A} 3$ adenosine receptor antagonists (US6,528,516B1). 2003; US: University of Pennsylvania.

125. Mitchell CH, Peterson-Yantorno K, Carré DA, McGlinn AM, Coca-Prados M, Stone RA, et al. A3 adenosine receptors regulate $\mathrm{Cl}-$ channels of nonpigmented ciliary epithelial cells. Am J Physiol Cell Physiol. 1999;276:C659-C666.

126. Gao ZG, Joshi BV, Klutz AM, Kim SK, Lee HW, Kim HO, et al. Conversion of A3 adenosine receptor agonists into selective antagonists by modification of the 5'-ribofuran-uronamide moiety. Bioorg Med Chem Lett. 2006;16:596-601.
127. Do CW, Peterson-Yantorno K, Mitchell CH, Civan MM. cAMPactivated maxi-Cl- channels in native bovine pigmented ciliary epithelial cells. Am J Physiol Cell Physiol. 2004;287: C1003-1011.

128. Jacobson KA, Park KS, Jiang JL, Kim YC, Olah ME, Stiles GL, et al. Pharmacological characterization of novel A(3) adenosine receptor-selective antagonists. Neuropharmacology. 1997;36:1157-65.

129. Jeong LS, Choe SA, Gunaga P, Kim HO, Lee HW, Lee SK, et al. Discovery of a new nucleoside template for human A3 adenosine receptor ligands: D-4'-thioadenosine derivatives without 4'hydroxymethyl group as highly potent and selective antagonists. J Med Chem. 2007;50:3159-62.

130. Okamura T, Kurogi Y, Hashimoto K, Sato S, Nishikawa H, Kiryu K, et al. Structure-activity relationships of adenosine A3 receptor ligands: new potential therapy for the treatment of glaucoma. Bioorg Med Chem Lett. 2004;14:3775-9.

131. Anighoro A, Bajorath J, Rastelli G. Polypharmacology: challenges and opportunities in drug discovery. J Med Chem. 2014;57:7874-87.

132. Lavecchia A, Cerchia C. In silico methods to address polypharmacology: current status, applications, and future perspectives. Drug Disco Today. 2016;21:288-98.

133. Bevan N, Butchers R, Cousins R, Coates J, Edgar V, Morrison V, et al. Pharmacological characterisation and inhibitory effects of (2R,3R,4S,5R)-2-(6-amino-2-\{[(1S)-2-hydroxy-1-(phenylmethyl) ethyl]amino $-9 H-p u r i n-9-y l)-5-(2-e t h y l-2 H-t e t r a z o l-5-y l) \quad$ tetra hydro-3,4-furandiol, a novel ligand that demonstrates both adenosine A2A receptor agonist and adenosine A3 receptor antagonist activity. Eur J Pharmacol. 2007;564:219-25.

134. Hou X, Majik MS, Kim K, Pyee Y, Lee Y, Alexander V, et al. Structure-activity relationships of truncated $\mathrm{C} 2-$ or $\mathrm{C} 8$ substituted adenosine derivatives as dual acting A2A and A3 adenosine receptor ligands. J Med Chem. 2012;55:342-56.

135. Gao ZG, Jacobson KA. Purinergic Signaling in Mast Cell Degranulation and Asthma Frontiers in Pharmacology. 2017;8:947-60.

136. Petrelli R, Torquati I, Kachler S, Luongo L, Maione S, Franchetti $\mathrm{P}$, et al. 5'-C-Ethyl-tetrazolyl-N6-substituted adenosine and 2chloro-adenosine derivatives as highly potent dual-acting A1 adenosine receptor agonists and $\mathrm{A} 3$ adenosine receptor antagonists. J Med Chem. 2015;58:2560-6.

137. Petrelli R, Scortichini M, Kachler S, Boccella S, Cerchia C, Torquati I, et al. Exploring the role of N6-substituents in potent dual acting 5'-C-ethyltetrazolyladenosine derivatives: synthesis, binding, functional assays, and antinociceptive effects in mice. $\mathrm{J}$ Med Chem. 2017;60:4327-41.

138. Barman S, Baumgartner R. WO2010/127210Al. Method of reducing intraocular pressure in humans. US: Inotek Pharmaceuticals Corp. Accessed 4 Nov 2010. 